\title{
International Journal of Production Economics \\ The impact of a store brand introduction in a supply chain with competing manufacturers: The strategic role of pricing and advertising decision timing --Manuscript Draft--
}

\begin{tabular}{|c|c|}
\hline Manuscript Number: & PROECO-D-21-00519R1 \\
\hline Keywords: & $\begin{array}{l}\text { OR in Marketing, Store and national brands, Advertising and pricing, Competitive } \\
\text { interactions, Game theory, Supply chain management }\end{array}$ \\
\hline Corresponding Author: & $\begin{array}{l}\text { Salma Karray, PhD } \\
\text { Ontario Tech University: University of Ontario Institute of Technology } \\
\text { Oshawa, ON CANADA }\end{array}$ \\
\hline First Author: & Salma Karray, PhD \\
\hline \multirow[t]{2}{*}{ Order of Authors: } & Salma Karray, PhD \\
\hline & Guiomar Martin-Herran, PhD \\
\hline Abstract: & $\begin{array}{l}\text { This research studies the impact of a store brand's introduction in a supply chain where } \\
\text { a retailer offers the national brands of competing manufacturers. The focus in this } \\
\text { paper is to study such impact given different manufacturers' decision timing choices } \\
\text { with regards to how they set pricing and advertising decisions. We develop a game- } \\
\text { theoretic model that is based on consumer utility functions to represent competition } \\
\text { between the national and store brands. We then solve six games to take into account } \\
\text { different decision timing choices. In particular, we consider whether manufacturers } \\
\text { decide of advertising before, after, or at the same time than pricing. Comparisons of } \\
\text { equilibrium profits for each supply chain member before and after store brand entry } \\
\text { under each decision timing scenario show that national brand manufacturers incur } \\
\text { losses as a result of the retailer's store brand when they keep their decision timing } \\
\text { unchanged. Interestingly, however, the retailer may restrain from introducing the store } \\
\text { brand especially if the national brand manufacturers set pricing decisions before } \\
\text { advertising, as is the case with fixed pricing contracts, and if the level of competition } \\
\text { between the national brands is sufficiently high. Further, manufacturers can } \\
\text { strategically change their decision timing to either benefit from, prevent or restrict } \\
\text { losses from the retailer's store brand. These results provide new insights on how } \\
\text { competitive interactions and contractual agreements in manufacturer-led supply chains } \\
\text { can impact the success of store brands for retailers and mitigate or intensify their threat } \\
\text { for national brands. }\end{array}$ \\
\hline
\end{tabular}


The impact of a store brand introduction in a supply chain with competing manufacturers: The strategic role of pricing and advertising decision timing ${ }^{1}$

\author{
Salma Karray ${ }^{2}$ \\ Ontario Tech University \\ 2000 Simcoe St N., L1G 0C5, Oshawa, ON, Canada \\ salma.karray@ontariotechu.ca \\ Tel. +1.905.721.8668 ext. 2832
}

Guiomar Martín-Herrán 3

IMUVA, Universidad de Valladolid, Spain

guiomar@eco.uva.es

\footnotetext{
${ }^{1}$ Declarations of interest: none

${ }^{2}$ Corresponding author. The author acknowledges the support of the Natural Sciences and Engineering Research Council of Canada (NSERC) [funding reference number RGPIN-2020-05156].

${ }^{3}$ The author gratefully acknowledges financial support from the Spanish Ministry of Science and Innovation and Universities, State Research Agency (AEI) under project ECO2017-82227-P and from Junta de Castilla y León under project VA169P20.
} 


\title{
The impact of a store brand introduction in a supply chain with competing manufacturers: The strategic role of pricing and advertising decision timing
}

\begin{abstract}
This research studies the impact of a store brand's introduction in a supply chain where a retailer offers the national brands of competing manufacturers. The focus in this paper is to study such impact given different manufacturers' decision timing choices with regards to how they set pricing and advertising decisions. We develop a game-theoretic model that is based on consumer utility functions to represent competition between the national and store brands. We then solve six games to take into account different decision timing choices. In particular, we consider whether manufacturers decide of advertising before, after, or at the same time than pricing. Comparisons of equilibrium profits for each supply chain member before and after store brand entry under each decision timing scenario show that national brand manufacturers incur losses as a result of the retailer's store brand when they keep their decision timing unchanged. Interestingly, however, the retailer may restrain from introducing the store brand especially if the national brand manufacturers set pricing decisions before advertising, as is the case with fixed pricing contracts, and if the level of competition between the national brands is sufficiently high. Further, manufacturers can strategically change their decision timing to either benefit from, prevent or restrict losses from the retailer's store brand. These results provide new insights on how competitive interactions and contractual agreements in manufacturer-led supply chains can impact the success of store brands for retailers and mitigate or intensify their threat for national brands.
\end{abstract}

Keywords: OR in Marketing, Store and national brands, Advertising and pricing, Competitive interactions, Game theory, Supply chain management

\section{Introduction}

The increasing dominance and growth of retailers' brands (store brands or private labels) is evident worldwide. Recent statistics show that private labels' market shares exceed 30\% in most European countries and reach as high as $40 \%$ in the UK and Germany (PLMA, 2020). In the US, private label sales have generated over $\$ 6.2$ billion in 2019 , which is equivalent to a growth rate of $4.6 \%$ in dollars and $3.2 \%$ in units.

The success of store brands has caused worry for national brand manufacturers who have seen their market shares shrink. This is especially relevant during the recent pandemic, as consumers have become more price sensitive. Recent consumer reports in the US show that the percentage of national brand retail sales is shrinking to the advantage of private labels (IRI, 2020). In fact, their 2020 first quarter sales surged by $\$ 4.9$ billion, which represents a nearly $15 \%$ year-over-year gain (Redman, 2020$)$.

In addition to increased sales, retailers can benefit from offering store brands in different ways. First, retail image and loyalty can be reinforced (Martenson, 2007, Collins-Dodd \& Lindley, 2003). Second, store brands can lead to economic benefits as retailers usually earn higher profit margins on their brands than on national brands. However, there are also drawbacks to store brand introductions. In fact, since they are usually offered at lower prices to consumers, store brands do not necessarily generate higher unit profits for retailers than national brands (Sudhir \& Talukdar, 2004). Further, private labels can lead to decreased willingness to pay for national brands (Steenkamp et al. 2010). This competition can strain relationships with national manufacturers (Pauwels \& Srinivasan, 2009), but can also indirectly benefit national brand demand through increased store patronage.

This research examines the economic impact of store brands' introduction. Different from previous studies, we investigate such impact for a supply chain where competing national brand manufacturers are selling 
their products through a common retailer. Manufacturers choose their local advertising expenditures and wholesale prices and the retailer decides on his local advertising and prices to consumers, as well as on whether or not to offer a store brand. To account for different decision timing scenarios in the supply chain, we study store brand introduction effects when prices are decided before, after, or simultaneously with advertising.

A growing theoretical literature examined the issue of private label introduction to identify whether there exist economic benefits from such products to national brand manufacturers and to retailers. The majority of works in this area focused on supply chains formed by one national brand manufacturer and one retailer, and on their pricing strategies. The main result from this literature has been that the retailer benefits from introducing his brand at the expense of the manufacturer. This is because the store brand presence leads to wholesale price concessions and can hurt demand for the national brand (e.g., Narasimhan \& Wilcox (1998); Pauwels \& Srinivasan (2004); Scott Morton \& Zettelmeyer (2004); Meza \& Sudhir (2010)).

In addition to making pricing decisions, manufacturers and retailers can engage in national and local advertising campaigns (Herrington \& Dempsey, 2005). National campaigns are usually aimed at increasing brand equity and can have carryover effects (Karray \& Zaccour. 2005), while local advertising's goal is to stimulate immediate demand (Pauwels, 2007) and generate brand switching (Chintagunta, 1993; Kumar \& Leone, 1988). This explains why companies allocate large budgets to local efforts. In fact, recent forecasts of local advertising expenditures in the US provide estimates of $\$ 161.3$ billion in 2020, and a corresponding growth rate of $5.8 \%$ (BIA, 2020).

In this paper, we focus on supply chain firms' local advertising activities. When undertaken by retailers, these activities include local advertising campaigns, as well as store flyers and in-store displays targeted at promoting specific products. Such marketing efforts are important for retailers. For example, it is estimated that store flyers account for over $50 \%$ of retailers' marketing budgets (Gázquez-Abad \& MartínezLópez, 2016), and can significantly impact consumer purchases (Guyt \& Gijsbrechts, 2018). Further, a large number of retailers allocate large investments for local TV and radio campaigns targeted at local markets (Borrell, 2018).

Manufacturers also invest in local advertising activities, which include local campaigns and special promotional events and offers (Forbes, 2020, Reed, 2020). For example, in 2007, the Nationwide Insurance company, a large insurance firm operating in the US, launched a billboard campaign focused only on the local Columbus market. Similarly, in 2014, Skittles, the candy brand, launched a campaign focused only on the Seattle area (Stevenson, 2018). Recently, Nike also launched a London-centric campaign. Finally, in Japan, KitKat chocolate brand offered customers the chance to print personalized messages on the wrapper and send via mail (Ernest-Jones, 2019). These examples show that local advertising efforts are prominent with national brand manufacturers in different industries (Borrell, 2018).

A few works have studied the retailer's choice to introduce a store brand taking into account local advertising decisions in the supply chain (Karray \& Zaccour, 2006, Karray \& Martín-Herrán, 2019). They find that when local advertising impacts are accounted for, the implications of store brand entry for the supply chain derived from pricing models do not necessarily hold. This is because adjustments in these advertising decisions at the manufacturing, retailing or both levels impact pricing strategies as well as the demands for both national and store brands, leading to a potential loss for the retailer or an increase of profitability for the national brand manufacturer.

Further, a limited number of studies have examined store brand introduction impacts for supply chains where a single retailer offers competing national brands. Similar positive impacts for the retailer have been noted when prices are the main decision variables (Raju et al., 1995, Sayman et al., 2002), as well as when quality is considered (Choi \& Coughlan, 2006, Chung \& Lee, 2017). Given that local advertising can affect the profitability of store brand entry in dyadic supply chains, it is important to study this problem while accounting for competition between national brands.

Recently, Karray \& Martín-Herrán (2019) found that the timing of pricing and advertising decisions set by the supply chain leader (manufacturer) affects the impact of a store brand introduction in a dyadic channel. This is relevant since different practices are observed in supply chains with regards to pricing and advertising decision timing depending on whether pricing agreements precede local advertising choices or vice versa, or whether these decisions are made simultaneously (Karray, 2013, Karray \& Martín-Herrán, 2019). 
In practice, the timing of pricing decisions can precede local advertising when, for example, an everyday low pricing (EDLP) strategy is implemented leading to fixed pricing contracts in the channel. In such cases, manufacturers commit to wholesale prices early on to avoid fluctuations in retail prices. However, local advertising efforts such as local campaigns and store displays are decided on a shorter planning period to stimulate demand. This EDLP strategy has been adopted by many retailers such as Walmart and Trader Joe's in the US and Tesco in the UK (Tang et al., 2014) and by their suppliers. For example, many manufacturers operating in industries with stable production processes such as food, grocery and ornaments set the same wholesale price for the entire selling season (Maiti \& Giri, 2017). Alternatively, pricing and advertising can have similar planning horizons and therefore be decided simultaneously. Finally, firms may have a longer planning horizon for advertising than for pricing either because of agreements with media agencies, budgetary constraints or strategic marketing objectives (Karray, 2013, Karray \& Martín-Herrán, 2019). For example, Vipshop, an online fashion retailer in China, resells thousands of products from branded manufacturers. Vipshop first posts the prices of its different brands, then decides to allocate different marketing efforts to the brands it resells based on different factors including their brand equity and sales performance. In this case, suppliers contract with Vipshop by first committing to a certain investment level to improve brand equity (e.g., advertising) and the retailer then sets its level of marketing effort to support each brand (Liu et al., 2018). Further, CPG manufacturers often fix their marketing effort budgets for the quarter or year when drafting their marketing plan, while their prices to retailers are delayed to a later period. Finally, in the electronics industry, prices are frequently changed to take advantage of technological innovations or seasonal changes, while advertising campaigns are set up front (Maiti \& Giri, 2017).

The implications of these different decision timing choices have not been studied for store brand entry in supply chains with competing manufacturers. Further, Karray \& Martín-Herrán (2019) consider decision timing to be exogenous to their model and do not endogenously solve for the optimal manufacturer's decision timing when the retailer is considering a store brand introduction. Therefore, their results cannot inform manufacturers on how they can use their decision timing strategically to influence the implications of a store brand entry.

Given these gaps in the literature, we aim to answer the following research questions:

1. When the decision timing for pricing and local advertising decisions is exogenously set, does a retailer benefit from introducing a store brand considering national brand competition and local advertising strategies? When the retailer benefits from offering a store brand, how is national brands' profitability impacted?

2. How does store brand profitability vary across different pricing and advertising decision timing scenarios?

3. When decision timing is endogenously determined by manufacturers, what is the optimal timing when the retailer is considering a store brand introduction?

To answer these research questions, we develop a game-theoretic model for two competing national brand manufacturers selling through a common retailer. We use a utility-based demand formulation that takes into account competition between national brands and between national and store brands. In our model, each supply chain member chooses its pricing and local advertising strategies and the retailer decides whether or not to introduce a store brand. Similar to most theoretical literature, we consider that the manufacturers lead the supply chain. However, we study different decision timing scenarios for pricing and advertising. In particular, we consider that manufacturers are leaders and they each either: (1) decide on advertising and pricing simultaneously, (2) decide on advertising, then on pricing, or (3) choose their prices before they announce their advertising strategies. We solve for equilibrium solutions in six games corresponding to each decision timing scenario with and without the store brand. We first consider that the decision timing is exogenously set and compare equilibrium solutions obtained from games with and without the store brand given the same decision timing. Such comparisons allow us to answer our first two research questions and assess the profitability of a store brand introduction under each of the three different decision timing scenarios, as well as compare effects across scenarios. Then, we consider that the manufacturers can endogenously set the decision timing for pricing and advertising following the retailer's decision to introduce (or not) a store brand. In this case, we answer our third research question by comparing equilibrium solutions obtained in the different decision timing scenarios.

Our research contributes to the existing theoretical literature by combining these different features: (1) 
we study store brand effects for a supply chain with competing national brands; (2) in addition to pricing decisions, we model local advertising choices of the competing manufacturers, as well as of the retailer; (3) while focusing on manufacturers-led supply chains, we study three scenarios of decision timing for pricing and advertising to reflect different practices and contractual agreements in the supply chain; and (4) we study the case where manufacturers can strategically set decision timing following the retailer's decision to introduce the store brand.

The remainder of this paper is organized as follows. Section 2 discusses the literature relevant to this paper. Section 3 outlines our model and assumptions. Section 4 describes the six games considered in this study. Section 5 reports the equilibrium solutions for each game and Section 6 presents the results of our analyses. Finally, Section 7 concludes and discusses future research.

\section{Literature review}

There are two main streams of literature related to this study. The first one is about the economic effects of store brand entry. The second relates to decision timing choices.

\subsection{Effects of a store brand introduction}

A large literature has explored issues related to retailers' store brands. We focus our review on theoretical studies about the impact of store brand introduction in a supply chain context. Most works in this field considered dyadic supply chains where a national brand manufacturer sells through an exclusive retailer. In such a context, the retailer can benefit from introducing a store brand, mainly because doing so would lower the national brand's wholesale price and allow the retailer to expand his sales volume (Narasimhan \& Wilcox, 1998; Gruca et al. 2001; Pauwels \& Srinivasan, 2004). Results from this literature also indicate that while the retailer finds it beneficial to offer a store brand, the national brand manufacturer does not. This is due to the price concessions given to the retailer and to the lower sales resulting from consumer demand switching to store brands (e.g., Pauwels \& Srinivasan (2004); Meza \& Sudhir (2010)).

Further, this literature dealt mainly with pricing issues. A few exceptions are noted where other decision variables have been modeled such as quality and advertising. Related to this study, research that took into account advertising decisions include Soberman \& Parker (2006), who find that when the national brand manufacturer supplies the store brand to the retailer, the manufacturer's national advertising can improve its position against the private label. Karray \& Zaccour (2005) solve a differential game to take into account the long-term impacts of national advertising and do not solve for prices. Further, Karray \& Zaccour (2006) consider that the manufacturer can subsidize the retailer's local advertising for his brand and can use such subsidy to minimize the harmful impact of the store brand. Karray \& Martín-Herrán (2009) develop a dynamic model for advertising and pricing competition between national and store brands but do not assess the impact of store brand entry. Amrouche \& Yan (2015) explore whether a manufacturer's national advertising can help it fight the store brand's harmful impacts. Without focusing on the impact of a store brand introduction, Chen \& Dimitrov (2015) identify conditions under which the manufacturer should not invest in national brand advertising. Recently, Karray \& Martín-Herrán (2019) model both retail and manufacturer local advertising decisions to assess whether national brand manufacturers can alleviate the harmful impacts of store brand entry by choosing different pricing and advertising decision timing scenarios in a dyadic channel.

All these studies indicate that advertising is a key variable in understanding the competition between store and national brands through its impact on demand and on pricing decisions for both the retailer and the manufacturer (Sethuraman, 2009). However, they have focused on a supply chain set-up where firms do not face competition. Because advertising can play an important role in building preference for the brand, it is important to consider competition for both pricing and advertising.

Theoretical works related to store brand impacts in supply chains with competing national brands are scarcer and mainly focused on pricing issues (Raju et al. 1995; Sayman et al., 2002, Scott Morton \& Zettelmeyer. 2004). Raju et al. (1995) develop game-theoretic models to study store brand entry in a supply chain formed by one retailer and two national brands. They show that the levels of price competition between the national brands and between the store and the national brands affect the profitability of the store brand. In particular, the introduction of a private label benefits the retailer when the cross-price sensitivity among national brands 
is low and the cross-price sensitivity between the store and the national brands is high. Sayman et al. (2002) and Scott Morton \& Zettelmeyer (2004) focus on optimal positioning strategies of the store brand against the competing national brands. Different from these works that mainly modeled pricing, a few studies consider the store brand quality decision (Choi \& Coughlan, 2006, Chung \& Lee, 2017). Finally, Karray \& Martín-Herrán (2008, 2009) solve for both advertising and pricing but do not focus on assessing the impact of the store brand entry. This paper contributes to this stream of research by accounting for both pricing and local advertising decisions in a supply chain with competing manufacturers.

\subsection{Decision timing}

The impact of decision timing on firms' strategies has been mainly studied in the game theory literature. In fact, the first-mover advantage is a well-known example of how decision timing can impact the equilibrium payoff of players. This means that whether decisions are made simultaneously or sequentially, and the order of the sequence in which they are made can have an important impact on the equilibrium outcome of the game (Gal-Or, 1985, 1987). Consequently, some studies have solved for the optimal decision timing in different non-cooperative games (e.g., see Bagwell (1995); Mailath (1993); Madden \& Pezzino (2019); van Damme \& Hurkens (1996, 1999, 2004); Hamilton \& Slutsky[(1990)).

In the supply chain and marketing literature, the implications of decision timing were mainly discussed in terms of how a leadership change in a Stackelberg game can impact economic payoffs (Etgar, 1977, Schul et al., 1983; Jørgensen et al., 2001, Choi et al., 2013). In this context, the Stackelberg leader is the firm that can pre-commit to an action, which must be taken into account by the other firms in the channel as they make their decisions (Weitz \& Wensley, 2002). A few studies have explored the problem of decision timing for competing firms, without supply chain considerations. For example, Perdikaki et al. (2016) investigate how competing retailers should time their service investments and pricing decisions when demand is uncertain. They show that retailers can benefit from setting their service levels prior to prices.

More closely related to our paper, a few studies in the supply chain area examined the optimal timing of different decisions, given a specific leadership structure between manufacturers and retailers. For example, assuming manufacturer leadership, a few papers studied the timing of manufacturer's direct and wholesale prices in a dual channel (Matsui, 2018, 2020; Liu \& Ke, 2020, Yan et al., 2020). They found that whether manufacturers decide of direct prices before or after their wholesale prices has a significant impact on profits. Applications of decision timing to problems that involve pricing and non-pricing decisions are scarce. Notably, Karray (2013) examined how different decision timing choices for advertising and price in a supply chain with one manufacturer and one retailer can impact profits and equilibrium strategies given different channel leadership scenarios.

In the store brand literature, most works considered manufacturer-Stackelberg games. When other decision variables than prices have been modeled, the assumption is that the retailer(s) and the manufacturer(s) make each of their decisions simultaneously. In our knowledge, Karray \& Martín-Herrán (2019) is the only work that explored how different choices for decision timing can influence the impact of a store brand entry. They considered a supply chain formed by one manufacturer and one retailer and showed that the profitability of store brand entry changes significantly whether the manufacturer, who is the channel leader, sets his advertising or pricing first or whether he makes both decisions simultaneously. This is because the sequence in which pricing and advertising decisions are announced changes the information available to each player when optimizing strategies at different stages of the game, hence impacting the supply chain members' reactions and outcomes at equilibrium. We contribute to this stream of research by accounting for different decision timing choices in a supply chain with competing manufacturers.

In summary, the theoretical literature about store brand introduction in dyadic channels points to the importance of advertising decisions in the supply chain. Yet, no study so far has modeled such variables when assessing the retailer's decision to introduce a private label given competing national brands. Further, similar to the literature about dyadic channels, works that have modeled competing national brands focus on manufacturer-led supply chains. When additional decision variables to prices are considered, the common assumption is that the retailers and the manufacturers make each of their decisions simultaneously. Our study contributes to this existing literature as follows:

1. We study store brand introduction effects considering both pricing and local advertising decisions of competing national brands' manufacturers selling through a common retailer; and 
2. We focus on a manufacturer-led channel and consider three different decision timing scenarios for pricing and advertising to reflect different practices and contractual contexts in the supply chain.

\section{Model}

Consider a distribution channel formed by two competing national brand manufacturers selling their products through a common retailer. Each manufacturer $i(i=1,2)$ chooses his national brand wholesale price $\left(w_{i}\right)$ and local advertising effort $\left(a_{m i}\right)$, while the retailer sets the national brand retail prices, $p_{i}\left(p_{i}>w_{i}\right)$, and the local advertising efforts for each national brand $\left(a_{r i}\right)$. Local advertising are non-price promotions aimed at stimulating short-term sales and include activities such as features and displays for retailers and contests, sweepstakes and local media ads for manufacturers (Reid et al., 2005; Kalra \& Shi, 2010). The retailer can introduce a store brand, in which case he will also set his price $\left(p_{s}\right)$ and local advertising effort $\left(a_{s}\right)$. A summary of all notations used in the model is presented in Table 1.

We consider that the utility function of a representative consumer is given by

$$
U=\sum_{k=1,2, s}\left(g_{k} q_{k}-q_{k}^{2} / 2-p_{k} q_{k}\right)-\theta \sum_{i=1,2}\left(q_{i} q_{s}\right)-\gamma q_{1} q_{2}
$$

where $q_{s}$ and $q_{i}$ represent the demand functions for the store and the national brand $i$, respectively, and $g_{k}$ $(k=i, s)$ is given by $g_{i}=v_{i}+\alpha a_{m i}+\beta a_{r i}(i=1,2)$ and $g_{s}=v_{s}+\beta a_{s}$.

This linear-quadratic utility formulation has been commonly used in the marketing and economics literature (e.g., Samuelson (1974); Spence (1976); Ingene \& Parry (2007); Cai et al. (2012); Liu et al. (2014); Karray et al. (2017); Karray \& Martín-Herrán (2019)). It exhibits the classical economic properties that: 1. The representative consumer's utility of owning a product decreases as the consumption of the substitute product increases; 2 . The marginal utility for a product diminishes as the consumption of the product increases; and 3. The value of using multiple substitutable products is less than the sum of the separate values of using each product on his own (Samuelson, 1974).

The expressions $g_{k}(k=i, s)$ represent the expanded base utility of brand $k$. It consists of a baseline utility $\left(v_{k}\right)$ increased by the positive local advertising effects undertaken for the product. For simplicity, we assume that the baseline utility of consuming each national brand is given by $v_{i}=v$. To differentiate between the national brand manufacturers' and the retailer's local advertising effects, we model them separately through the positive parameters $\alpha$ and $\beta$, respectively. Substitutability between the national brands and the store brand is represented by the parameter $\theta \in(0,1)$, while competition between the national brands is modeled by $\gamma \in(0,1)$. The values of these parameters increase with more competition between the relevant products.

We assume a static consumer demand which is reasonable since local advertising activities (non-price promotions, contests, etc.) effects on demand are usually immediate with low carryover effects (Reid et al. 2005, Kalra \& Shi, 2010). Further, the baseline utility for national brands $(v)$ is assumed to be higher than the store brand's base utility $\left(v_{s}\right)$, which reflects built-up equity for the national brands through, for example, past national advertising campaigns. Also, we don't consider dynamic pricing in our model, which applies to products with infrequent price adjustments (e.g., durable products, luxury goods, etc.). Finally, our model is deterministic to represent a stable market where consumer response to different marketing instruments can be easily predicted (e.g., in mature markets) and firms' behaviors are not volatile.

Maximization of the representative consumer surplus $U-\sum_{k=1,2, s}\left(p_{k} q_{k}\right)$ with regards to demands leads to the following store brand's $\left(q_{s}\right)$ and national brands' $\left(q_{i}\right)$ demand functions for $i, j=1,2, i \neq j$ :

$$
\begin{aligned}
q_{i}= & \frac{1}{(1-\gamma)\left(1+\gamma-2 \theta^{2}\right)}\left[\left(v-\theta v_{s}\right)(1-\gamma)+\left(1-\theta^{2}\right)\left(\alpha a_{m i}+\beta a_{r i}-p_{i}\right)-\left(\gamma-\theta^{2}\right)\left(\alpha a_{m j}+\beta a_{r j}-p_{j}\right)\right. \\
& \left.-\theta(1-\gamma)\left(\beta a_{s}-p_{s}\right)\right], \\
q_{s}= & \frac{1}{\left(1+\gamma-2 \theta^{2}\right)}\left[(1+\gamma) v_{s}-2 \theta v+(1+\gamma)\left(\beta a_{s}-p_{s}\right)-\theta \sum_{i=1,2}\left(\alpha a_{m i}+\beta a_{r i}-p_{i}\right)\right] .
\end{aligned}
$$

Note that these demand functions are linear in prices and local advertising efforts. The advantage of using this formulation instead of an aggregate demand function is that modeling consumer utility provides meaningful interpretations of the model parameters. In aggregate demand functions, the impact of each decision 
variable on demand is commonly represented by a single parameter. This utility-based demand shows a much richer formulation of all of the marginal-utility variables (see Choi \& Coughlan (2006) and Lus \& Muriel (2009) for more discussion on the value of utility-based demand formulations).

Before we write the profit functions and problems for each supply chain firm, we make the following few assumptions. First, we consider that the store brand is provided to the retailer by an external and unbranded manufacturer. Second, the production costs of the national and the store brands are assumed null for simplicity. Third, the local advertising costs of the manufacturers and the retailer are quadratic to represent increasing marginal costs of advertising. Fourth, other supply chain decisions are assumed exogenous to the model. These assumptions are commonly used in the theoretical literature about store brand introductions (see Sethuraman (2009) for a review showing the commonality of these assumptions) and about supply chains (e.g., Ingene \& Parry (2007); Cai et al. (2012)).

In case the retailer decides to offer the store brand, the profit maximization problems of the national brand manufacturers $\left(M_{i}\right)$ and of the retailer $(R)$ are given by

$$
\begin{aligned}
\max _{w_{i}, a_{m i}} M_{i} & =w_{i} q_{i}-a_{m i}^{2}, \quad i=1,2, \\
\max _{p_{i}, p_{s}, a_{s}, a_{r i}} R & =\sum_{i=1,2}\left[\left(p_{i}-w_{i}\right) q_{i}-a_{r i}^{2}\right]+p_{s} q_{s}-a_{s}^{2} .
\end{aligned}
$$

The model for the scenario where the retailer does not offer the store brand can be obtained by setting $v_{s}, \theta, p_{s}, a_{s}$ and $q_{s}$ to zero.

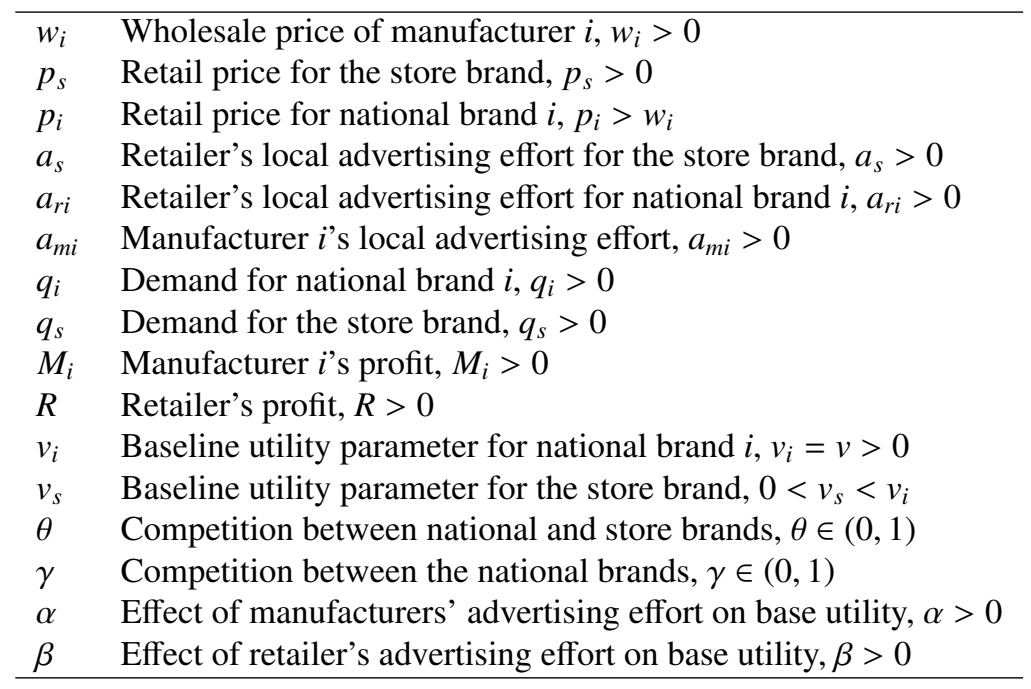

Table 1: Notation

\section{Decision timing scenarios (games)}

We consider six games in order to analyze the impact of store brand introduction on the supply chain members' strategies and profits given different decision timing scenarios. In each of these games, we assume that the manufacturers make their decisions simultaneously (play Nash) and are leaders, while the retailer is a follower. These assumptions are common in industries where companies use similar marketing planning practices (Sudhir, 2001, Sethuraman, 2009, Ingene et al., 2012). This means that the manufacturers always announce their decisions first and the retailer takes into account the manufacturers' decisions when choosing his own. We also assume that the retailer reacts by making the same kind of decision(s) (pricing, advertising or both) than those announced by the manufacturers (Karray, 2013; Karray \& Martín-Herrán. 2019). We focus our analysis on the effect of a store brand introduction in a manufacturer-led channel where retailers cannot set a decision type (advertising or pricing) before observing the manufacturers' same decision. We make this assumption in order to formally separate the issue of channel leadership (who should be the channel leader(s) for which decision) from the issue of decision timing (which decision(s) should 
the channel leaders make first). Most importantly, this assumption is crucial for pursuing our research objectives, which are focused on the impact of a store brand introduction, and what manufacturers, as channel leaders can do to manage its harmful effects. Given the manufacturers' leadership assumption, there are many possible decision timing scenarios. In order to focus on the issue of how price vs. local advertising timing can affect store brand introduction given a specific channel leadership structure, we focus on six games. Three of these relate to the cases where the retailer does not offer the store brand $(S, A P, P A)$ and the remaining three to the alternative $\left(S^{S B}, A P^{S B}, P A^{S B}\right)$. We present the decision timing scenarios for these games by focusing on the three following cases.

1. Simultaneous price and advertising decisions (games $S$ and $S^{S B}$ ): Each of these games is played in two stages. First, national brand manufacturers play Nash and they each set their advertising and pricing decisions simultaneously $\left(w_{i}\right.$ and $a_{m i}$ ). Knowing the manufacturers' decisions, the retailer then reacts by also setting both his relevant advertising and pricing strategies $\left(p_{i}\right.$ and $a_{r i}$ in $S$ and $p_{i}, p_{s}, a_{s}$ and $a_{r i}$ in $S^{S B}$ ). Comparisons of equilibrium solutions obtained in games $S$ and $S^{S B}$ will help analyze the impacts of store brand introduction under this decision timing scenario.

2. Sequential decision timing where advertising decisions are made before prices (games $A P$ and $A P^{S B}$ ): Each of these games is played in four stages. First, national brand manufacturers play Nash and they each decide on their advertising strategies. Second, the retailer sets his relevant advertising decisions, knowing the manufacturers' advertising levels. Third, the manufacturers play Nash and set their wholesale prices, knowing the retailer's advertising decisions and their own. Fourth, the retailer decides of his relevant retail prices, knowing the manufacturers' advertising and wholesale prices as well as his advertising levels. Comparisons of equilibrium solutions obtained in games $A P$ and $A P^{S B}$ will help analyze the impacts of store brand introduction under this decision timing scenario.

3. Sequential decision timing where advertising decisions are made after prices (games $P A$ and $P A^{S B}$ ): Each of these games is also played in four stages. First, manufacturers play Nash and announce their wholesale prices. Second, the retailer sets his relevant retail prices knowing the manufacturers' prices. Third, the manufacturers play Nash and set their advertising strategies knowing the retailer's prices and their own. Finally, the retailer sets his relevant advertising levels, knowing all previously announced decisions. Comparisons of equilibrium solutions obtained in games $P A$ and $P A^{S B}$ will help analyze the impacts of store brand introduction under this decision timing scenario.

\section{Equilibrium solutions}

We solve each of the six games described in the previous section by backward induction. Appendix 1 provides a detailed description of the solution methodology and expressions of the reaction functions and second-order conditions for each game. Note that, in all games, we obtain equilibrium solutions that are symmetric for the manufacturers' products so we delete the index $i$ for simplicity. Since the expressions of the players' profits are lengthy, we have omitted them here for ease of presentation. Finally, in Appendix 1, we also identify the feasible region for each of the six games $\left(S^{S B}, A P^{S B}, P A^{S B}, S, A P\right.$ and $\left.P A\right)$, which is defined by the parameter space in $v, v_{s}, \alpha, \beta, \theta$ and $\gamma$ where both the positivity and concavity conditions are satisfied in the corresponding game. Specifically, we characterize the interior equilibrium conditions in each game to check that the obtained equilibrium solutions verify: 1 . the positivity conditions for all prices, advertising, demands, margins and profits, and 2. the concavity (second-order) conditions ensuring that the extrema are interior maxima.

For simplicity, we only present here the analytical expressions of the equilibrium solution for the three games involving a store brand $\left(S^{S B}, A P^{S B}, P A^{S B}\right)$. The equilibrium solution for the games where no store brand is offered can be obtained by setting $\theta=v_{s}=0$. Note that, given a decision timing scenario, the retailer's decisions and the problem of each supply chain member will differ depending on whether a store brand is offered or not (see Appendix 1).

\subsection{Advertising and prices are decided simultaneously}

In the simultaneous scenarios ( $S$ and $S^{S B}$ ), each game is played in two stages. We start by solving the retailer's problem in advertising and prices and then use the obtained reaction functions to write the manufacturers' profit functions and solve their problems simultaneously to get the equilibrium manufacturers' advertising and wholesale prices. 
Proposition 1. The equilibrium solution obtained in game $S^{S B}$ is included below

$$
\begin{aligned}
a_{m}^{S} & =\frac{\alpha\left[\left(4-\beta^{2}\right) v-4 v_{s} \theta\right] X}{\alpha^{2}\left(\beta^{2}-4\right) X+2\left[X+2\left(\beta^{2} \gamma+4 \theta^{2}-4 \gamma\right)\right]\left[X-4\left(\beta^{2} \gamma+4 \theta^{2}-4 \gamma\right)\right]}, \\
w^{S} & =\frac{\left(\beta^{2}+4 \gamma-4\right)\left[X-4\left(4 \theta^{2}-4 \gamma+\beta^{2} \gamma\right)\right]}{\alpha X} a_{m}^{S}, \\
a_{r}^{S} & =\frac{\beta}{\alpha} a_{m}^{S}, \\
a_{s}^{S} & =\frac{\beta\left(v_{s}\left(4-\beta^{2}+4 \gamma\right)-8 \theta\left(v+\alpha a_{m}^{S}-w^{S}\right)\right)}{\beta^{4}-4(\gamma+2) \beta^{2}+16\left(\gamma-2 \theta^{2}+1\right)}, \\
p_{s}^{S} & =\frac{4 \beta^{2}\left(v+\alpha a_{m}^{S}-w^{S}\right) \theta+2 v_{s}\left(\beta^{2}+8 \theta^{2}-4(1+\gamma)\right)}{\left(4-\beta^{2}\right)\left(\beta^{2}-4(1+\gamma)\right)+32 \theta^{2}}, \\
p^{S} & =\frac{\beta^{2}\left(\left(4-\beta^{2}\right) w^{S}+2 \theta v_{s}\right)+\left(16 \theta^{2}+2(1+\gamma)\left(\beta^{2}-4\right)\right)\left(v+\alpha a_{m}^{S}+w^{S}\right)}{\left(4-\beta^{2}\right)\left(\beta^{2}-4(1+\gamma)\right)+32 \theta^{2}},
\end{aligned}
$$

where

$$
X=\left(\beta^{2}-4\right)^{2}-16 \theta^{2}
$$

5.2. Advertising is decided prior to prices

In the sequential games where advertising is decided prior to pricing $\left(A P\right.$ and $A P^{S B}$ ), each game is played in four stages. We start by solving for the retailer's prices then use them to write the manufacturers' problems. The latter are solved simultaneously to get the wholesale prices. We then use the obtained expressions of both prices to write the retailer's problem and solve it in the retail advertising strategies. The solution, along with all other pricing variables, are then injected in the manufacturers' problems, which are then solved simultaneously to obtain the equilibrium advertising strategy for each national brand manufacturer.

Proposition 2. The equilibrium solution obtained in game $A P^{S B}$ is included below

$$
\begin{aligned}
& a_{m}^{A P}=\frac{16 \alpha(1-\gamma)\left(1-\theta^{2}\right)\left(\gamma-2 \theta^{2}+1\right)\left(\gamma+\theta^{2}-2\right)\left[\left(\beta^{2}-4\right) v+4 v_{s} \theta\right] Y_{1}}{Y_{2}}, \\
& a_{r}^{A P}=\frac{\beta\left[\left(4-\beta^{2}\right)\left(\alpha a_{m}^{A P}+v\right)-4 v_{s} \theta\right]\left(\theta^{2}-1\right)^{2}}{\beta^{4}\left(\theta^{2}-1\right)^{2}-4 \beta^{2}\left(\gamma^{2}(\gamma-3)-3(\gamma-2) \theta^{2}\left(\theta^{2}-2\right)+5\right)+16\left(\gamma+\theta^{2}-2\right)^{2}\left(\gamma-2 \theta^{2}+1\right)}, \\
& a_{s}^{A P}=\frac{\beta v_{s}\left[4(\gamma+1)(\gamma-2)^{2}-4(3 \gamma-5)\left(\theta^{2}-2\right) \theta^{2}\right]-\left[8 \theta\left(\alpha a_{m}^{A P}+v\right)+\beta^{2} v_{s}\right]\left(\theta^{2}-1\right)^{2}}{\beta^{4}\left(\theta^{2}-1\right)^{2}-4 \beta^{2}\left[\gamma^{2}(\gamma-3)-3(\gamma-2) \theta^{2}\left(\theta^{2}-2\right)+5\right]+16\left(\gamma+\theta^{2}-2\right)^{2}\left(\gamma-2 \theta^{2}+1\right)}, \\
& p^{A P}=\frac{\left(2 \gamma+\theta^{2}-3\right)\left(\alpha a_{m}^{A P}+\beta a_{r}^{A P}+v\right)+\theta(1-\gamma)\left(\beta a_{s}^{A P}+v_{s}\right)}{2\left(\gamma+\theta^{2}-2\right)}, \\
& p_{s}^{A P}=\frac{\beta a_{s}^{A P}+v_{s}}{2}, \quad \frac{(\gamma-1)\left[\alpha a_{m}^{A P}+\beta\left(a_{r}^{A P}-\theta a_{s}^{A P}\right)+v-\theta v_{s}\right]}{\gamma+\theta^{2}-2}, \\
& w^{A P}=\frac{(\gamma}{2},
\end{aligned}
$$

where

$$
\begin{aligned}
Y_{1}= & \left(\theta^{2}-1\right)^{2} \beta^{4}-4\left[(\gamma-3) \gamma^{2}-3 \theta^{2}\left(\theta^{2}-2\right)(\gamma-2)+5\right] \beta^{2}+16\left(\gamma+\theta^{2}-2\right)^{2}\left(\gamma-2 \theta^{2}+1\right), \\
Y_{2}= & {\left[\beta^{2}\left(\theta^{2}-1\right)^{2}+4(\gamma-1)\left(\gamma-3 \theta^{2}+2\right)^{2}\right] Y_{1}^{2}-16 \alpha^{2}\left(\beta^{2}-4\right)(\gamma-1)\left(\theta^{2}-1\right)\left(\gamma-2 \theta^{2}+1\right)\left(\gamma+\theta^{2}-2\right) \times } \\
& {\left[\beta^{4}\left(\theta^{2}-1\right)^{3}-8\left(\gamma-3 \theta^{2}+2\right)\left(\gamma+\theta^{2}-2\right)\left(\gamma^{2}-2(\gamma-2) \theta^{2}-\theta^{4}-2\right)\right.} \\
& \left.+2 \beta^{2}\left(\gamma \theta^{2}\left(9 \theta^{4}-4 \gamma(\gamma-3)-13\left(2 \theta^{2}-1\right)\right)+\gamma^{2}\left(\gamma^{2}-6\right)-\theta^{2}\left(14 \theta^{4}-41 \theta^{2}+36\right)+10\right)\right] .
\end{aligned}
$$




\subsection{Prices are decided prior to advertising}

A four-stage game is played when prices are decided prior to advertising $\left(P A\right.$ and $\left.P A^{S B}\right)$. In these games, we start by solving the retailer's problem in advertising decisions then use them to write the manufacturers' problems. The latter are solved simultaneously to get the national brands' advertising strategies. Next, the obtained expressions are used to write the retailer's problem, which is then solved in the retail prices. Finally, we inject all obtained solutions in the manufacturers' problems, which are solved simultaneously to get the equilibrium wholesale prices.

Proposition 3. The equilibrium solution obtained in game $P A^{S B}$ is included below

$$
\begin{aligned}
w^{P A} & =\frac{4(\gamma-1)^{2}\left(4-\beta^{2}-4 \gamma\right)\left(\gamma-2 \theta^{2}+1\right)^{2}\left[\left(\beta^{2}-4\right) v+4 v_{s} \theta\right]}{Z}, \\
p^{P A} & =\frac{\alpha^{2}\left(1-\theta^{2}\right)\left[\left(\beta^{2}-4\right)(\gamma+1)+8 \theta^{2}\right]+(1-\gamma)\left(\gamma-2 \theta^{2}+1\right)\left[16 \theta^{2}-\left(\beta^{2}-4\right)\left(\beta^{2}-2(\gamma+1)\right)\right]}{(1-\gamma)\left(\gamma-2 \theta^{2}+1\right)\left[\left(4-\beta^{2}\right)\left(\beta^{2}-4(\gamma+1)\right)+32 \theta^{2}\right]} w^{P A}, \\
p_{s}^{P A} & =2 \frac{\beta^{2} \theta\left[\theta^{2}\left(\alpha^{2}+4 \gamma-4\right)-\alpha^{2}-2\left(\gamma^{2}-1\right)\right]+(\gamma-1)\left(\gamma-2 \theta^{2}+1\right)\left[2 \beta^{2} v \theta+v_{s}\left(\beta^{2}-4(\gamma+1)+8 \theta^{2}\right)\right]}{(1-\gamma)\left(\gamma-2 \theta^{2}+1\right)\left[\left(4-\beta^{2}\right)\left(\beta^{2}-4(\gamma+1)\right)+32 \theta^{2}\right]} w^{P A}, \\
a_{r}^{P A} & =\frac{\beta\left[p^{P A}-w^{P A}-\theta p_{s}^{P A}\right]}{2\left(\gamma-2 \theta^{2}+1\right)}, \\
a_{s}^{P A} & =\frac{\beta\left[2 \theta\left(w^{P A}-p^{P A}\right)+(1+\gamma) p_{s}^{P A}\right]}{2\left(\gamma-2 \theta^{2}+1\right)}, \\
a_{m}^{P A} & =\frac{\alpha\left(\theta^{2}-1\right) w^{P A}}{2(\gamma-1)\left(\gamma-2 \theta^{2}+1\right)},
\end{aligned}
$$

where

$$
\begin{aligned}
Z= & \alpha^{2} \beta^{6}\left(\theta^{2}-1\right)^{2}+4 \beta^{4}\left[\alpha^{2}\left(\theta^{2}-1\right)\left(2+\gamma^{2}-(2 \gamma+1) \theta^{2}\right)-2(\gamma-1)^{2}\left(\gamma-2 \theta^{2}+1\right)^{2}\right] \\
& +8 \beta^{2}\left[\alpha^{2}\left(1-\theta^{2}\right)\left(-\gamma^{3}+2 \gamma^{2}+2(\gamma(2 \gamma-5)-1) \theta^{2}+\gamma+4 \theta^{4}+2\right)-2(\gamma-4)(\gamma-1)^{2}\left(\gamma-2 \theta^{2}+1\right)^{2}\right] \\
& +32(\gamma-1)\left(\gamma-2 \theta^{2}+1\right)\left[\theta^{4}\left(\alpha^{2}-4 \gamma+4\right)-\theta^{2}\left(\alpha^{2}(\gamma+1)+2(\gamma-5)(\gamma-1)\right)+\alpha^{2} \gamma+2 \gamma^{3}-4 \gamma^{2}-2 \gamma+4\right] .
\end{aligned}
$$

\section{Effects of the store brand introduction}

To answer our research questions, we compare the equilibrium profits obtained under each of the three different decision timing scenarios considered in the paper. We start our analysis for the case where the manufacturers cannot change their decision timing choice after the store brand entry. Then we relax this assumption.

\subsection{The manufacturers cannot change their decision timing following the store brand entry}

In this section, we consider that the decision timing for pricing and local advertising decisions is exogenously set and study whether a retailer would benefit from introducing a store brand under each decision timing scenario. When market conditions are such that the retailer benefits from offering a store brand, we determine whether national brand manufacturers gain or lose from the private label entry. To do so, we compare solutions obtained in games $S$ and $S^{S B}, A P$ and $A P^{S B}$ and $P A$ and $P A^{S B}$. For each pair of games, these comparisons are done when both games' equilibrium solutions are feasible, meaning that the positivity and concavity conditions are satisfied in both games.

Given the complexity of the solutions in Proposition 1-3, we cannot obtain any meaningful analytical insights from these comparisons. This is why we resort to an exhaustive numerical analysis approach, which consists in fixing the values of some parameters in the model while varying others in acceptable ranges given the feasible equilibrium domain identified for each game. In particular, we fix $v=1$ and $v_{s}=0.6$ to represent the common situation where the national brands are stronger than the store brand. Then, we perform the analysis for all possible combinations of the parameters $\theta$ and $\gamma$ such as; $\theta \in\{0.15,0.25,0.35\}$ 
and $\gamma \in\{0.2,0.4,0.6\}$. This yields nine numerical scenarios. For each of these, we numerically evaluate the signs of the analytical expressions of profit and strategies' comparisons considering all possible and feasible combinations of parameters $\alpha$ and $\beta$ in a grid of $(0,3)$ for $\alpha$ and $(0,2)$ for $\beta$ with a mesh of 0.001 . For each of the nine numerical scenarios corresponding to combinations of $\theta$ and $\gamma$ in the feasible domain, we obtain the results for 5,000 value combinations of parameters $\alpha$ and $\beta$. In total, this means that our numerical analysis was performed for 45,000 combinations of numerical values. This same numerical approach is used to analyze the impact of store brand introduction on equilibrium prices and advertising strategies (See Table A.1 in Appendix 2).

When relevant, we present some results in figures showing $\alpha$ and $\beta$ in the axes for different fixed values of $\gamma$ and $\theta$. In these figures, the signs "+" and "-" mean that the effect of the store brand introduction is positive or negative, respectively. The sign "UF" denotes that, in the designated region, the solution is unfeasible. This means that at least one of the positivity or concavity conditions of the equilibrium strategies in the represented games is not verified.

The next claims discuss the profitability of the store brand introduction for the retailer and the manufacturers. Claims 1 to 3 have been derived by comparing the retailer's equilibrium profits under the nine numerical scenarios described above, considering 5,000 feasible value combinations of parameters $\alpha$ and $\beta$ with $\alpha$ in $(0,3)$ and $\beta$ in $(0,2)$.

Claim 1. The retailer's equilibrium profit is higher in game $S^{S B}$ than in game $S$.

Claim 1 shows that the retailer benefits from introducing the store brand when each manufacturer simultaneously sets his pricing and advertising decisions. Such result holds for any level of competition level between the store and the national brands $(\theta)$ and between the national brands $(\gamma)$, as well as for any level of local advertising effects by the manufacturers and the retailer ( $\alpha$ and $\beta$ ).

Comparison of equilibrium strategies in the simultaneous games $S$ and $S^{S B}$ provides more insights into this result (see Table A.1 in Appendix 2). It shows that, for most values of the model parameters, the manufacturers charge higher wholesale prices and invest more in local advertising efforts following the retailer's decision to introduce the SB. The retailer passes on this price increase to consumers through higher NB retail prices. He also spends more on local advertising efforts. Overall, the negative effect of higher retail prices on NB demand is offset by the positive impact of higher advertising efforts, resulting in larger NB demand after the SB entry.

Therefore, to fight against the competitive pressure from the new store brand, manufacturers boost their revenue through increased margins and more aggressive local advertising spending. This indicates that the retailer's decision to introduce a SB aggravates the double marginalization problem in the supply chain, which forces all channel members to invest more in advertising efforts in order to stimulate the NB demand. The retailer benefits from the SB despite his inflated advertising costs and higher wholesale prices for two reasons. First, the SB entry forces the manufacturers to increase their advertising support. Second, the additional SB sales generate enough additional revenues to offset any losses due to increased retail costs.

Interestingly, this claim contradicts findings in the literature that only considered pricing decisions in dyadic or competitive channels, which indicated that a store brand entry may not benefit the retailer (Raju et al. 1995: Sayman et al. 2002). Also, this result differs from previous works that considered dyadic channels and modeled advertising decisions. In particular, Karray \& Martín-Herrán(2019) found that, under a simultaneous decision timing scenario, the retailer does not always benefit from the store brand entry when the manufacturers' local advertising effort is very effective and there is low competition between the store and the national brand. Our result shows that taking into account manufacturers' competitive interactions annihilates this case. In fact, the manufacturers' advertising, even when very effective in stimulating demand, does not generate large enough demand expansion effects in a competitive environment to deter the retailer from introducing the store brand.

Claim 2. The retailer's equilibrium profit is higher in game $A P^{S B}$ than in game AP for most parameters' values.

Claim 2 indicates that, when local advertising is decided before pricing, the retailer's profit increases following the store brand entry for most parameters' values in the feasible domain. This results holds for all levels of advertising effects under specific competitive market conditions. In particular, the retailer benefits 
from the store brand entry when the national brands are not close substitutes $(\gamma \in 0.2,0.4)$ for any level of competition between the store and national brands $(\theta)$.

Comparisons of equilibrium strategies and demand in games $A P^{S B}$ and $A P$ provide further explanation for these results (Table A.1 in Appendix 2). They show that, for most values of the model parameters, whenever the retailer benefits from the store brand, all equilibrium prices, advertising and national brand demand are higher in game $A P^{S B}$ than in $A P$. Therefore, the retailer's profit gain is generated by the revenue expansion due to the new SB sales and by the expansion in NB demand.

However, as Figure 1 shows, when competition intensity between the national brands is high $(\gamma=0.6)$, the store brand introduction can lead to lower retail profit. This occurs when the market is characterized by low levels of both competition between the store and national brands $(\theta)$ and the manufacturers' advertising effect $(\alpha)$, coupled with very high levels of the retailer's advertising effect $(\beta)$. Figure 1 illustrates the retailer's profit comparisons in this case. It shows that for $\theta=0.15$ and $\gamma=0.6$, while the private label boosts the retail profit for most values of advertising effects, it can lead to retail losses for high ranges of $\beta$ coupled with low levels of $\alpha$. Comparisons of equilibrium strategies and demand in games $A P^{S B}$ and AP (Table A.1 in Appendix 2) show that, under these conditions, all equilibrium prices, advertising and NB demand are higher after the SB introduction. Because the national brands compete closely $(\gamma=0.6)$, their demand is highly impacted by the competitive pressures from each other and from the SB, which is aggravated by the high retail advertising effect $(\beta)$. Ultimately, under these conditions, the retailer's revenue expansion is not large enough to offset the NB purchasing and advertising cost inflation, resulting in an overall retail loss.

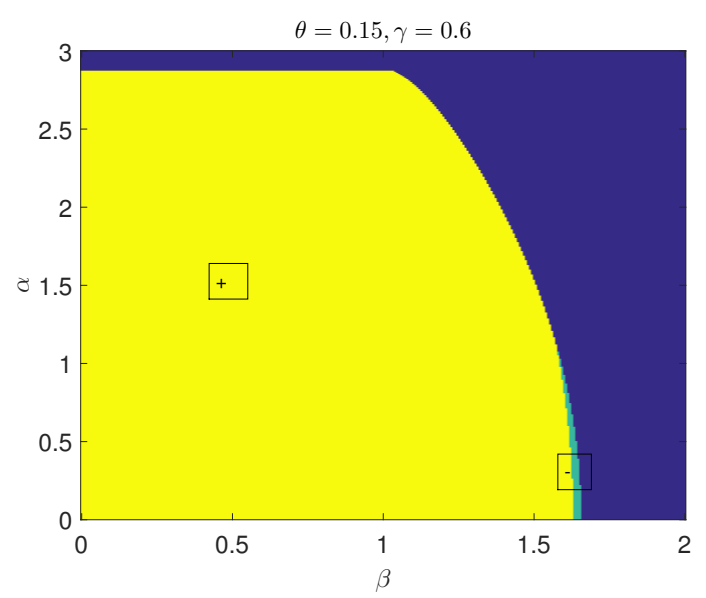

Figure 1: Effect of SB introduction on the retailer's profit when advertising is decided prior to pricing.

Note that this result differs from previous research that considered a similar decision timing scenario for a dyadic channel. In fact, while Soberman \& Parker (2006) also find that a private label is not always beneficial to the retailer in a dyadic channel, the store brand in their model is supplied by the national brand manufacturer and the retailer does not invest in advertising. Further, Karray \& Martín-Herrán (2019) find that the retailer should introduce the private label in most cases when local advertising is decided before pricing, except for low levels of competition between the store and national brands and very high levels of both manufacturer and retail advertising effects. Contrary to their finding, Claim 2 suggests that when manufacturer competition is accounted for, the retailer's loss becomes limited to the situation where national brands' competition is intense (the brands are not well differentiated) and only retail advertising is very effective. These differences show how national brand advertising effects can change the impact of a store brand introduction. They highlight the complexity of different competitive interactions between store and national brands and between national brands as well as the impact of manufacturer and retailer advertising efforts play an important role in influencing store brand profitability.

Claim 3. The retailer's equilibrium profit can be higher or lower in game $P A^{S B}$ than in game $P A$.

This result shows that when pricing is decided before local advertising, the retailer can gain or lose from in- 
troducing the store brand. We find that store brand profitability is highly linked to the degree of competition between the different products in the market. In particular, the private label increases the retailer's profit for any level of advertising effects $(\alpha$ and $\beta$ ) in the following cases: 1 . Competition between the national brands is low $(\gamma=0.2)$ and competition between the store and national brands is moderate to high $(\theta=0.25,0.35)$, and 2. Competition between the national brands is moderate $(\gamma=0.4)$ while competition between the store and national brands is high $(\theta=0.35)$. Hence, the retailer benefits from offering the SB when the national brands are differentiated enough from each other but are close enough substitutes to the store brand.

Comparison of equilibrium strategies in games $P A^{S B}$ and $P A$ indicates that the gain in retail profitability is mainly due to higher NB revenues generated by increased NB retail prices and demand (Table A.1 in Appendix 2). Despite the fact that retail advertising costs are also higher in the $P A^{S B}$ than in the $P A$ game, the retailer's revenue expansion can offset such cost inflation under the market conditions mentioned above.

In all other competitive scenarios, the levels of advertising effects significantly impact the profitability of the store brand for the retailer. Figure 2 shows results of retail profits comparisons in games $P A^{S B}$ and $P A$ for values of $\theta$ and $\gamma$ that lead to a positive or negative impact. As we can see, in these cases, the store brand's profitability depends on the two types of competition (both $\theta$ and $\gamma$ ), and on the advertising effectiveness levels $(\alpha$ and $\beta)$.

From Figure 2, we can make two main observations. First, looking at the competition levels, we can see that when $\theta$ is low, a negative impact of the store brand can be observed for all levels of $\gamma$. Therefore, the retailer does not benefit from introducing a differentiated SB. Alternatively, with higher levels of $\theta$, such negative impact only occurs for higher levels of $\gamma$. This means that the retailer does not benefit from introducing a SB that competes closely with the NB if the latter are also close competitors.

Second, the specific ranges of $\alpha$ and $\beta$ for which the retail profit decreases vary depending on the values of $\theta$ and $\gamma$. However, we consistently find that the retailer does not profit from introducing the store brand when $\beta$ is high. The explanation for this result lies in the fact that, when the retailer's advertising efforts are highly effective, the increase in the retailer's advertising costs exceeds the benefit from additional NB demand and SB sales.

Compared to the other two timing scenarios, the equilibrium strategies in the $P A$ games are similarly impacted by the SB introduction (mostly an increase in all prices, advertising efforts and NB demand). However, the magnitudes of these effects are different, which leads to the SB being predominately profitable for the retailer in the $A P$ and $S$ scenarios while not always beneficial in the $P A$ game.

These insights are different from the case of a dyadic channel. Karray \& Martín-Herrán (2019) find that, under this decision timing scenario, the only case where the retailer does not benefit from a store brand entry is for high manufacturer advertising effects coupled with low substitutability levels between the national and store brands. Therefore, accounting for competition between the national brands provides very important new results as it shifts the emphasis from manufacturer to retailer advertising effects and shows the role of national brands' competition intensity.

Next, we look at the impact of the store brand entry for the national brand manufacturers. Claim 4 has been derived by comparing the manufacturers' profits in the different decision timing scenarios before and after the retailer introduces the store brand. These comparisons have been done under the nine numerical scenarios described at the beginning of Subsection 6.1 and for any $\alpha$ in $(0,3)$ and $\beta$ in $(0,2)$ with a mesh of 0.01 .

Claim 4. Whenever the retailer benefits from introducing the store brand, the manufacturers' profits decrease in all decision timing scenarios.

This result shows that store brand entry is harmful to the national brand manufacturers no matter the decision timing for pricing and advertising. It generalizes previous findings in the literature, which showed that store brands could be a threat to national brands' dominance. It further shows that a pre-commitment to advertising, pricing or to both does not change such a threat. The reason for this finding lies in how manufacturers adjust their equilibrium strategies following the retailer's decision to introduce a SB. As discussed before, in all decision timing scenarios, we find that manufacturers react in a similar way to a SB entry. Namely, they increase their wholesale prices and advertising efforts, which leads the retailer to also charge higher prices and invest more in NB advertising efforts. This, ultimately, expands the manufacturers' 

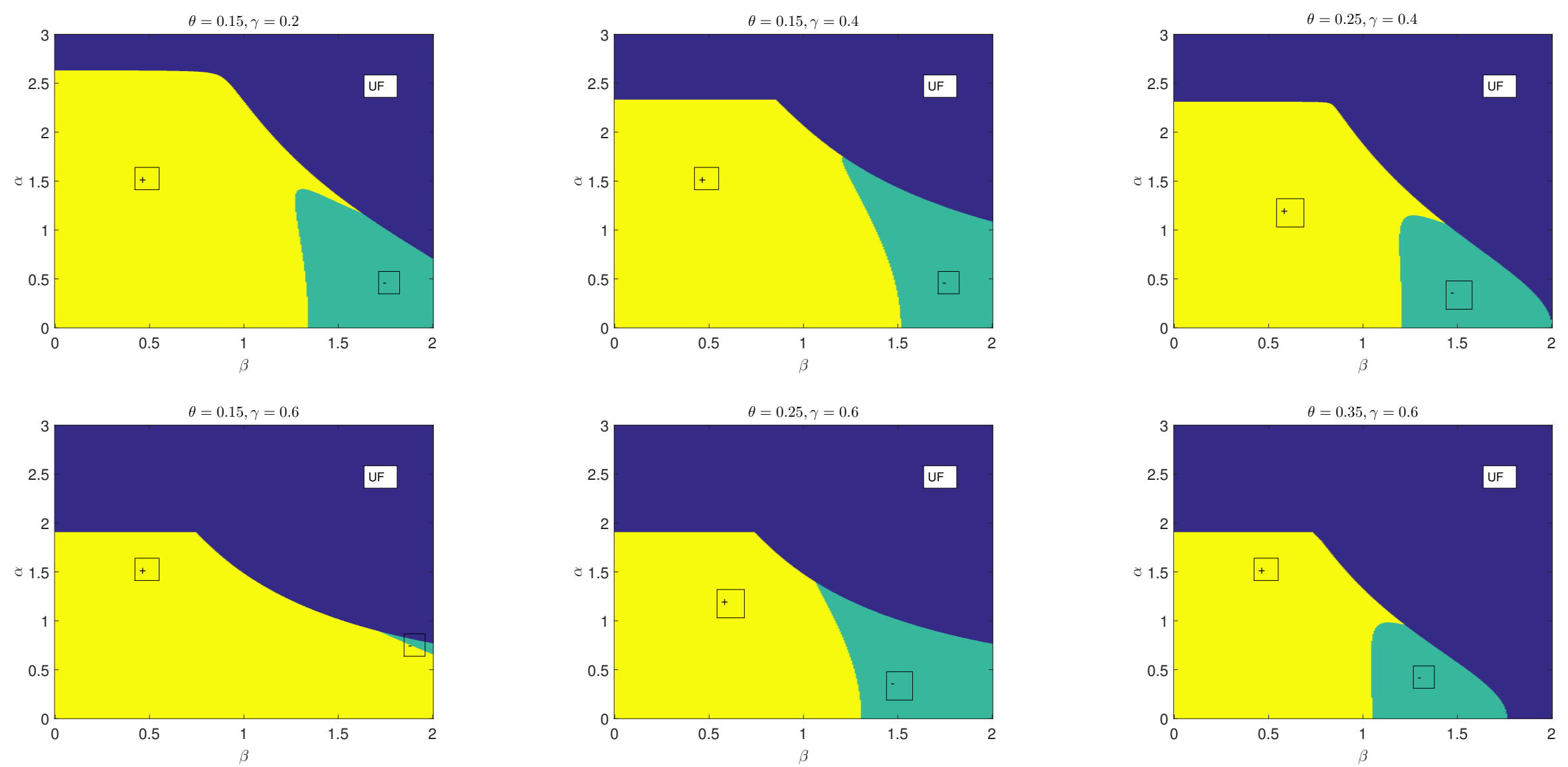

Figure 2: Effect of SB introduction on the retailer's profit when advertising is decided after pricing. 

Appendix 2).

The main insight from this finding is that manufacturers cannot prevent the negative impact of the store brand if they keep the same decision timing than the one chosen before the store brand entry. Given that manufacturers incur losses whenever the retailer introduces a store brand, the only way in which such a loss can be prevented is if the retailer finds the store brand unprofitable too. According to Claims 1 to 3 , this occurs when advertising and pricing are not decided simultaneously and is more likely when pricing precedes advertising. As shown in Claim 3, an early commitment to pricing decisions can make the store brand entry unattractive when the retailer uses effective local advertising activities, when the planned store brand does not compete intensely with the national brands (e.g., a store brand that is packaged differently or is of distinctly inferior quality), and/or when the manufacturers' products are close substitutes. This is mainly because the store brand introduction will not lead to significant price increase as in the other previous decision timing scenarios and the manufacturers can better adjust their levels of advertising to boost their demand and revenues. Next, we consider the case when manufacturers can choose their decision timing choice following the store brand entry.

\subsection{The manufacturers can choose their decision timing following the store brand entry}

In the previous section, we have studied the impact of store brand entry for the retailer and the competing manufacturers when the latter keep the same decision timing before and after the store brand introduction. The results we obtained in Claims 1 to 4 are useful when manufacturers either do not consider or cannot alter their decision timing (e.g., due to contractual commitments).

In this section, we address our third research question, namely; when decision timing is endogenously determined by manufacturers, what is the optimal timing when the retailer is considering a store brand introduction? To study this question, we expand our previous analysis to the case where manufacturers can choose a different decision timing following a store brand introduction. Given that manufacturers always lose when they keep their decision timing unchanged following a store brand addition (Claim 4), we focus the analysis in this section on whether manufacturers can strategically choose their decision timing to either change or minimize the negative impact of the store brand entry that would ensue when they keep their decision timing unchanged. In fact, when faced with the threat of a store brand entry, the manufacturers' optimal decision timing would allow them to benefit through one of the following three alternatives by decreasing order of preference; (1) profit from the store brand; (2) prevent its entry by choosing a decision timing that leads to an unprofitable store brand introduction for the retailer; or (3) minimize manufacturers' losses incurred due to store brand entry. The manufacturers would only choose the same decision timing as the benchmark scenario when these benefits cannot be achieved. Therefore, considering each benchmark decision timing $(S, A P$ and $P A)$, we investigate the following questions:

1. Can the manufacturers change their decision timing to benefit from a store brand entry?

2. If the manufacturers cannot benefit from a store brand entry, can they change their decision timing to prevent a store brand entry?

3. If the manufacturers cannot prevent nor benefit from the store brand entry, can they change their decision timing to minimize the losses they would have incurred had they kept the same decision timing?

Since our research objectives are focused on the impact of a store brand introduction, we make the following few assumptions. First, we assume that the decision timing in case the retailer does not consider offering a store brand is given as benchmark in our model $(S, A P$, or $P A)$. Second, we consider a symmetric scenario where each manufacturer chooses the same decision timing as the competitor. Third, when the retailer considers a store brand introduction, he announces whether a store brand will be introduced or not before the manufacturers declare their decision timing. This last assumption allows us to analyze whether decision timing can be used by manufacturers to counter the negative store brand entry effects found in the previous section.

To answer our research questions, we apply the same numerical approach than the one conducted in the previous section to compare profits of the retailer and manufacturers. In particular, we consider the nine numerical scenarios described at the beginning of Subsection 6.1 and the same grid for parameters $\alpha$ and $\beta$. 
To answer the first question, for each benchmark decision timing scenario ( $S, A P$ and $P A$ ), we characterize the $\alpha-\beta$ region such that the manufacturers are interested in changing their decision timing to benefit from a store brand entry. For example, if the benchmark scenario is $S$, the manufacturers should change to scenario $A P$ if the retailer obtains more profits under scenario $A P^{S B}$ than under scenario $S$ and simultaneously the manufacturers' profits under scenario $A P^{S B}$ are greater than the maximum of their profits under scenarios $S, S^{S B}$ and $P A^{S B}$.

To answer the second question, for each benchmark decision timing scenario ( $S, A P$ and $P A$ ), we characterize the $\alpha-\beta$ region such that the manufacturers are interested in changing their decision timing to prevent a store brand entry. For example, if the benchmark scenario is $S$, the manufacturers cannot benefit from a store brand entry, and hence their profits under scenario $S$ are greater than the maximum of their profits under scenarios $S^{S B}, A P^{S B}$ and $P A^{S B}$. Furthermore, to prevent a store brand entry, the manufacturers should change to either scenario $A P$ or scenario $P A$ if the retailer's profits under the benchmark scenario $S$ are greater than under scenarios $A P^{S B}$ or $P A^{S B}$, respectively.

Finally, when the manufacturers cannot change their decision timing to prevent nor benefit from the store brand entry, we characterize the $\alpha-\beta$ region such that the manufacturers are interested in changing their decision timing to minimize the losses they would have incurred had they kept the same decision timing. Assuming again, for example, that the benchmark scenario is $S$, on one hand, the manufacturers' profits under scenario $S$ are greater than the maximum of their profits under scenarios $S^{S B}, A P^{S B}$ and $P A^{S B}$. On the other hand, the retailer's profits under the benchmark scenario $S$ are lower than in any of the decision timing scenarios after the store brand entry, $S^{S B}, A P^{S B}$ and $P A^{S B}$. The manufacturers should change to scenario $A P^{S B}$ (respectively $P A^{S B}$ ) if their profits under this scenario are greater than the profits they should get under scenarios $S^{S B}$ and $P A^{S B}$ (respectively $S^{S B}$ and $A P^{S B}$ ).

The results reported below in Claim 5 summarize the answers to the research questions previously described.

Claim 5. For each benchmark decision timing scenario (S, AP and PA), the manufacturers can strategically change their decision timing to either benefit from, prevent or limit losses incurred due to a store brand introduction by the retailer.

Claim 5 shows that, when faced with the threat of a store brand entry by the retailer, the manufacturers can strategically choose their decision timing for pricing and local advertising decisions to limit the harmful effects of the private label introduction. Next, we further explore the result in Claim 5. In particular, we discuss market conditions and present some numerical examples (Figures 3-5) showing the different benefits resulting from a decision timing change.

\subsubsection{The manufacturers change their decision timing to benefit from a store brand entry}

In the best case scenario, a change in decision timing can revert the harmful effects of a store brand by making it profitable for all channel members. The market conditions conducive for such effects differ depending on the benchmark scenario. For example, Figure 3.a shows that when the benchmark is $S$, manufacturers can benefit from a store brand entry when they change their decision timing to $A P^{S B}$ in markets characterized by low enough levels of $\theta$. This is because a pre-commitment to advertising in game $A P^{S B}$ allows manufacturers to lower their local advertising investments compared to game $S^{S B}$. Despite the fact that the demand for their products shrinks as a result, the advertising cost saving is significant enough to overcome the loss in manufacturers' revenue for market conditions shown in Figure 3.a (Table A.2 in Appendix 2). Similarly, when the benchmark is $A P$, changing to game $S^{S B}$ after the store brand entry can increase both manufacturer and retailer NB advertising, which results in NB demand expansion (Table A.2 in Appendix 2). The resulting gain in manufacturers' revenues can offset any loss due to additional advertising investments for market conditions shown in Figure 3.b.

However, when the benchmark is $A P$, market conditions conducive for such effects are characterized by low levels of $\gamma$. Finally, when the benchmark is $P A$, the analysis of market conditions shows that low enough levels of $\theta$ are required when $\gamma$ is low but higher values of $\theta$ are observed when $\gamma$ is high. Further, for each benchmark scenario, different levels of the advertising effects are required (see Figure 3 ). These results are driven by the impact of the channel members' strategic decision timing. When there is an early commitment to either price or local advertising, these decisions may be set either below or above their optimal levels in the simultaneous game. Consequently, changing the decision timing after the store brand entry can adjust the levels of these decisions to guarantee a profitable output for the manufacturers. 


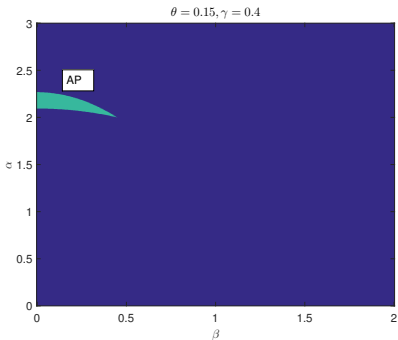

(a) S benchmark

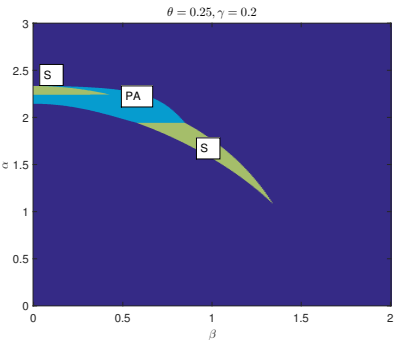

(b) AP benchmark

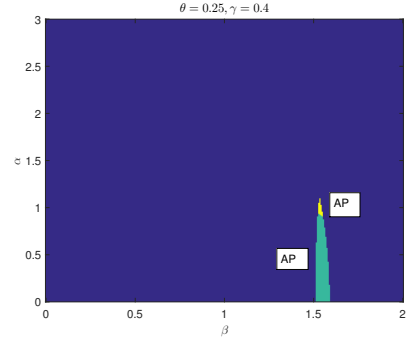

(c) PA benchmark

Figure 3: Regions where the manufacturers should change their decision timing to benefit from a store brand entry

\subsubsection{The manufacturers change their decision timing to prevent a store brand entry}

If manufacturers cannot benefit from a store brand entry, their next best option is to strategically change their decision timing in order to make the store brand unprofitable for the retailer, and therefore prevent its entry altogether. Our numerical analysis shows that manufacturers could prevent the store brand entry for any level of $\theta$ and $\gamma$. However, this strategy can only be adopted for specific values of advertising effects, which depend on the decision making process in place at the time of considering the store brand entry, as well as on the levels of competition among the national and store brands.

For example, when game $S$ or $A P$ is the benchmark, manufacturers can prevent the store brand entry for high enough levels of $\alpha$ or $\beta$. Everything else being the same, the parameter region where such strategy can be implemented seems to increase with higher levels of $\theta$ or $\gamma$ for the $A P$ benchmark, while the opposite was found for the $S$ benchmark case. However, when the benchmark is $P A$, very low as well as very high levels of $\alpha$ or $\beta$ can be favorable to prevent store brand entry with larger regions observed for higher $\theta$ and lower $\gamma$ (see Figure 4).

Figure 4 illustrates many examples where changing the decision timing after the store brand entry can adjust the levels of price and advertising decisions in a way that renders store brand entry unprofitable for the retailer, thereby preventing manufacturers from suffering the losses they would have incurred had they kept their decision timing unchanged. For example, when the benchmark is $A P$, changing to game $S^{S B}$ or $P A^{S B}$ after the store brand entry can increase retail advertising for the NB and decrease it for the SB (Table A.2 in Appendix 2). This leads to limiting the retailer's revenue from selling the SB and increasing his advertising costs, which renders competition from the store brand undesirable for the retailer's overall category profit.

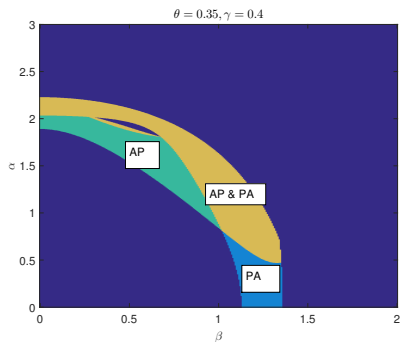

(a) S benchmark

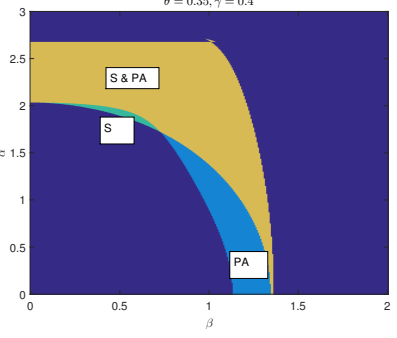

(b) AP benchmark

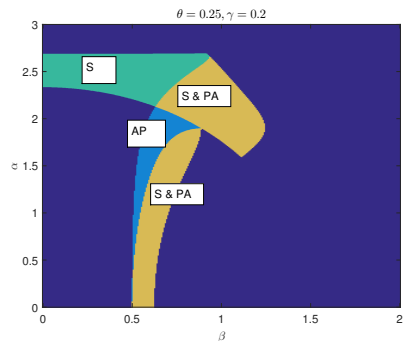

(c) PA benchmark

Figure 4: Regions where the manufacturers should change their decision timing to prevent a store brand entry.

\subsubsection{The manufacturers change their decision timing to minimize the losses they would have incurred had they kept the same decision timing}

Even when manufacturers cannot prevent nor benefit from the store brand entry, they can still strategically change their decision timing to alleviate the harmful effect of a store brand entry. Our results indicate that manufacturers could limit their losses from the store brand entry for low enough levels of $\alpha$ or $\beta$. The specific values of advertising effects that are favorable for this strategy depend on the decision making 
process in place at the time of considering the store brand entry, as well as on the levels of competition among the national and store brands.

For example, when game $S$ or $P A$ is the benchmark, manufacturers can minimize their losses for all levels of competition $(\theta$ and $\gamma$ ). Everything else being the same, the parameter region where such strategy can be implemented seems to increase with higher levels of $\gamma$ and decrease with higher $\theta$. For the $A P$ benchmark, manufacturers losses can be minimized through a change in decision making only for low enough values of $\gamma$ with the parameter region where such benefit can be realized decreasing with higher levels of both $\gamma$ and $\theta$ (see Figure 5).

These examples clearly show that even when the store brand entry cannot be avoided, manufacturers still can use a decision timing change strategy in order to minimize their losses after the store brand entry. The explanation lies again in the impact of decision timing on the firms' price and advertising investments and in turn on their revenues and costs. For example, when the benchmark is $P A$, changing to game $A P^{S B}$ after the SB introduction will decrease manufacturers' advertising investment (Table A.2 in Appendix 2), thereby improving their profitability.

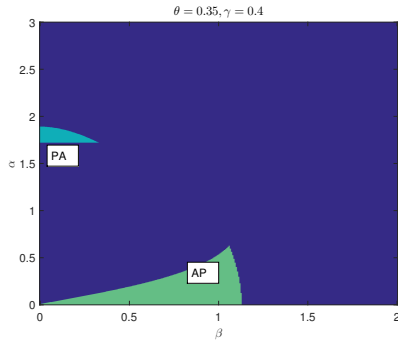

(a) $\mathrm{S}$ benchmark

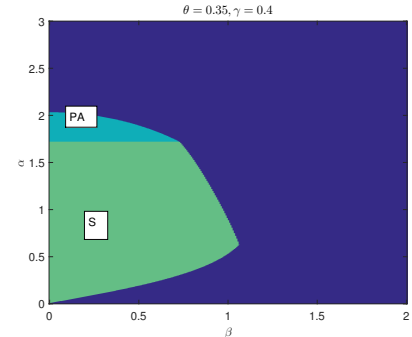

(b) AP benchmark

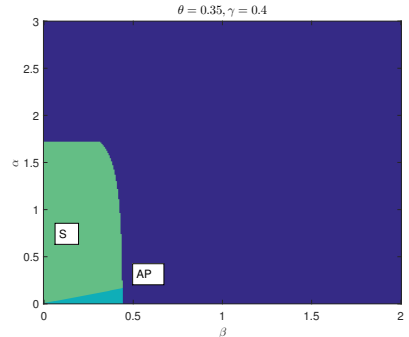

(c) PA benchmark

Figure 5: Regions where the manufacturers should change their decision timing to minimize the losses they would have incurred had they kept the same decision timing.

These results show that manufacturers can revert the harmful effects of store brands by simply changing their decision-making process (timing) of their prices and advertising. However, they can only do so under specific market conditions depending on the decision making process in place at the time of considering the store brand entry, as well as on the levels of competition among the national and store brands and the advertising effects of the retailer and manufacturers. Finally, compared to Karray \& Martín-Herrán (2019), our analysis provides a clear outline of how manufacturers can benefit from a decision timing change through one of the three benefits highlighted above. It also identifies the optimal decision timing strategy for competing manufacturers.

\section{Conclusions}

Store brands have become prevalent worldwide. The theoretical literature has offered many valuable insights about the impacts of such brands for the retailer and the national brands' manufacturers. However, no research has yet studied the impact of the retailer's decision to introduce a store brand in a supply chain with competing manufacturers taking into account both pricing and local advertising strategies as well as the discrepancy in the timing of these decisions.

This paper addresses this research gap. We develop a game-theoretic model using a utility-based consumer demand to account for substitutability between two national brands and between the store and the national brands and the impact of both pricing and local advertising efforts on consumer utility and therefore demand. Local advertising activities include a variety of non-price promotional efforts aimed at stimulating immediate demand ranging from direct mail, store flyers, product displays, contests, etc. We consider that the manufacturers lead the supply chain and solve six games to account for different decision timing scenarios. This is to reflect different contractual practices in supply chains where commitments to pricing can be made before advertising decisions or vice-versa or where both decisions are made simultaneously. 
Comparison of equilibrium solutions with and without store brand presence under each decision timing scenario provides the following results. First, we find that the national brand manufacturers incur losses whenever the retailer decides to introduce a store brand. This is mainly because of the higher advertising efforts ensued by the store brand entry, which leads to lower manufacturers' profits despite an increase in their revenues. These findings support results from the literature that pointed to the threat of store brands for national brands and generalize these results to setups where local advertising effects are modeled, manufacturers' competition is taken into account and different decision timing scenarios of pricing and advertising are accounted for.

Since manufacturers' losses would only occur if the retailer benefits from adding the store brand to its product portfolio, analysis of store brand profitability for the retailer shows that the latter may restrain from introducing the store brand. Our results indicate that this may happen when the national brand manufacturers pre-commit to pricing decisions before announcing their local advertising strategies as is the case in fixed-pricing contracts (e.g., in supply chains that apply everyday low pricing strategies). In this case, the store brand is detrimental to the retailer whenever the level of competition between the national brands is sufficiently high and the retailer's advertising activities are very effective. This is because, under these conditions, the store brand addition leads to higher advertising costs for the retailer, which cannot be offset by the additional revenues generated by the SB.

Finally, in all other cases, specifically when pricing is announced before advertising but retail advertising is not highly effective or the level of national brands' substitutability is low, the retailer is better off with the store brand. In this case, advertising for the national brands does not generate enough revenues to counter the benefits from a store brand entry. For the other two decision timing scenarios where advertising is decided either simultaneously or prior to pricing, the retailer almost always benefits from adding the store brand. This result is driven mainly by the expansion of the retailer's revenue due to higher advertising expenditures.

Compared to previous studies that have not modeled local advertising decisions, national brand competition or both, these results offer new insights about the importance of retail advertising effectiveness and the level of competitive intensity between store and national brands and between national brands when assessing the impacts of store brand entry in supply chains. They also show that when manufacturers pre-commit to pricing strategies before they announce local advertising decisions, store brands can be unappealing for retailers who invest in highly effective local advertising activities or are serving consumers who are highly sensitive to promotions.

We extend the analysis of store brand effects to the case where manufacturers can endogenously decide to alter their decision timing for pricing and local advertising when faced with the possibility of a store brand entry by the retailer. We find that a change in manufacturers' optimal decision timing would be beneficial either by leading to a profitable store brand entry for the manufacturers, by preventing the store brand from being introduced by the retailer, or by reducing the manufacturers' losses incurred due to store brand entry had the decision timing stayed the same. The specific benefit that can be gained depends on the benchmark decision timing implemented in the channel before the store brand introduction is considered, as well as on competitive intensity and advertising effects in the market.

Future research can extend this research in many ways. First, our model can be extended by accounting for retail competition. Some papers that have studied store brand entry decisions with supply chains formed by one manufacturer and competing retailers have found that results from dyadic channels do not necessarily hold. Second, given the fact that our findings point to the importance of the timing in which pricing and advertising decisions are made, similar analyses can be done considering other kinds of vertical interactions in the supply chain (Ru et al., 2015, Chung \& Lee, 2017). In particular, the manufacturers' leadership assumption can be relaxed to consider different alternative scenarios where the retailer is the channel leader, there is mixed leadership (the retailer leads in one decision while the manufacturers lead in others), or the channel members play vertical Nash to make one or many decisions. Third, we used a static and deterministic framework to address our research objectives. Our model can be extended to represent markets where there is a need for dynamic pricing, include dynamic effects of national advertising, or account for uncertainty in the market (e.g., Krishnamoorthy et al. (2010); Schlosser (2017); Helmes et al. (2013)). Fourth, we considered a decentralized channel where manufacturers make independent decisions. This can be relaxed by accounting for manufacturers' collusive behavior. Finally, future research can extend our 
model to the case of asymmetric manufacturers. Note that these extensions will considerably complicate the model as analytical solutions to the store brand games will be difficult to obtain.

\section{Appendix 1. Equilibrium for the $S^{S B}, A P^{S B}$ and $P A^{S B}$}

We obtain feedback equilibrium solutions using backward induction for the three games where the retailer does offer a store brand. The first game is $S^{S B}$, where the manufacturers decide simultaneously of advertising and pricing. In the second game, that is, $A P^{S B}$, the manufacturers decide of advertising prior to pricing. In the third game $\left(P A^{S B}\right)$, the manufacturers decide of pricing prior to advertising. In each of these three games, the retailer is the follower; he makes the same decision(s) than the manufacturers in the previous stage of the game.

The $S^{S B}$ game

In this case, the game is played in two stages. First, we consider the retailer's problem in the second stage given by

$$
\max _{p_{i}, p_{s}, a_{s}, a_{r i}} R=\sum_{i=1,2}\left[\left(p_{i}-w_{i}\right) q_{i}-a_{r i}^{2}\right]+p_{s} q_{s}-a_{s}^{2},
$$

where $q_{i}$ is given by (1) and $q_{s}$ in (2) and solve the following first-order equilibrium conditions:

$$
\frac{\partial R}{\partial p_{i}}=\frac{\partial R}{\partial a_{r i}}=\frac{\partial R}{\partial p_{s}}=\frac{\partial R}{\partial a_{s}}=0, \quad i=1,2,
$$

which yields the retailer's reaction functions to the manufacturers' decision variables, that is,

$$
\begin{aligned}
& p_{i}=\frac{a_{m i} \Delta_{1}+2 \beta^{2}\left(w_{j}-a_{m j} \alpha\right)\left(\left(\beta^{2}-4\right) \gamma+4 \theta^{2}\right)+w_{i} \Delta_{2}+\Delta_{3}}{\left(\beta^{2}-4(1-\gamma)\right)\left(\left(\beta^{2}-4\right)\left(\beta^{2}-4(1+\gamma)\right)-32 \theta^{2}\right)}, i, j=1,2, i \neq j, \\
& p_{s}=-\frac{2\left(\beta^{2} \theta\left(\alpha\left(a_{m 1}+a_{m 2}\right)+2 v-w_{1}-w_{2}\right)+v_{s}\left(\beta^{2}-4(1+\gamma)+8 \theta^{2}\right)\right)}{\left(\beta^{2}-4\right)\left(\beta^{2}-4(1+\gamma)\right)-32 \theta^{2}}, \\
& a_{r}=-\beta \frac{\left(\left(\beta^{2}-4\right)^{2}-16 \theta^{2}\right)\left(a_{m 1} \alpha-w_{1}\right)+4\left(a_{m 2} \alpha-w_{2}\right)\left(\left(\beta^{2}-4\right) \gamma+4 \theta^{2}\right)+\Delta_{4}}{\left(\beta^{2}-4\right)\left(\beta^{2}-4(1+\gamma)\right)-32 \theta^{2}}, \\
& a_{s}=\frac{\beta\left(4 \theta\left(-\alpha\left(a_{m 1}+a_{m 2}\right)-2 v+w_{1}+w_{2}\right)+v_{s}\left(-\beta^{2}+4(\gamma+1)\right)\right)}{\left(\beta^{2}-4\right)\left(\beta^{2}-4(1+\gamma)\right)-32 \theta^{2}},
\end{aligned}
$$

where

$$
\begin{aligned}
& \Delta_{1}=2 \alpha\left(4-\beta^{2}\right)\left(\beta^{2}-4\left(1-\gamma^{2}\right)\right)-8 \alpha \theta^{2}\left(\beta^{2}-8(1-\gamma)\right), \\
& \Delta_{2}=\left(\beta^{2}-4\right)\left(\beta^{2}\left(\beta^{2}-6\right)+8\left(1+\gamma^{2}\right)\right)-8 \theta^{2}\left(3 \beta^{2}-8(1-\gamma)\right), \\
& \Delta_{3}=2\left(\beta^{2}-4(1-\gamma)\right)\left(-v\left(\left(\beta^{2}-4\right)(\gamma+1)+8 \theta^{2}\right)-\beta^{2} v_{s} \theta\right), \\
& \Delta_{4}=\beta^{2}-4(1-\gamma)\left(\left(\beta^{2}-4\right) v+4 v_{s} \theta\right) .
\end{aligned}
$$

The study of the quadratic form associated with the Hessian matrix establishes that the retailer's profit is a strictly concave function in the decision variables $p_{i}, p_{s}, a_{r i}, a_{s}, i=1,2$ iff

$$
\begin{aligned}
& \gamma-2 \theta^{2}+1>0, \\
& \beta^{2}\left(\theta^{2}-1\right)+4(1-\gamma)\left(1+\gamma-2 \theta^{2}\right)>0, \\
& \left(\beta^{2}-4(1-\gamma)\right)\left(\beta^{2}-4(\gamma+1)+8 \theta^{2}\right)>0, \\
& -\beta^{6}+12 \beta^{4}+16 \beta^{2}\left(\gamma^{2}+2 \theta^{2}-3\right)-64\left(\left(\gamma-\theta^{2}\right)^{2}-\left(\theta^{2}-1\right)\right)>0 .
\end{aligned}
$$

We then insert the expressions of the retailer's reaction functions into the manufacturer $i$ 's optimization problem given by

$$
\max _{a_{m i}, w_{i}} M_{i}=w_{i} q_{i}-a_{m i}^{2}
$$


where $q_{i}$ is given by (1). The manufacturers play a Nash game and the first-order conditions for a Nash equilibrium are given by

$$
\frac{\partial M_{i}}{\partial w_{i}}=\frac{\partial M_{i}}{\partial a_{m i}}=0, \quad i=1,2 .
$$

The solution to the above system gives the equilibrium solution for $w_{i}$ and $a_{m i}$ in the $S^{S B}$ scenario presented in Proposition 1. The study of the quadratic form associated with the Hessian matrix establishes that the manufacturer $i$ 's profit is a strictly concave function in the decision variables $w_{i}, a_{m i}$ iff

$$
\begin{aligned}
& \frac{4\left(\left(\beta^{2}-4\right)^{2}-16 \theta^{2}\right)}{\left(\beta^{2}-4(1-\gamma)\right)\left(\left(\beta^{2}-4\right)\left(\beta^{2}-4(1+\gamma)\right)-32 \theta^{2}\right)}<0 \\
& 4\left(\left(\beta^{2}-4\right)^{2}-16 \theta^{2}\right)\left[\alpha^{2}\left(\left(\beta^{2}-4\right)^{2}-16 \theta^{2}\right)+2\left(\beta^{4}\left(\beta^{2}-12\right)-16 \beta^{2}\left(\gamma^{2}+2 \theta^{2}-3\right)\right.\right. \\
& \left.\left.\quad+64\left(\left(\gamma-\theta^{2}\right)^{2}-\left(\theta^{2}-1\right)\right)\right)\right]<0 .
\end{aligned}
$$

The $A P^{S B}$ game

In $A P^{S B}$, the game is played in four stages. To solve the game backwards, we start by stage 4 and solve the retailer's pricing problem given by

$$
\max _{p_{i}, p_{s}} R=\sum_{i=1,2}\left[\left(p_{i}-w_{i}\right) q_{i}-a_{r i}^{2}\right]+p_{s} q_{s}-a_{s}^{2}
$$

where $q_{i}$ is given by (1) and $q_{s}$ in $(2)$ and solve the following first-order equilibrium conditions:

$$
\frac{\partial R}{\partial p_{i}}=\frac{\partial R}{\partial p_{s}}=0, i=1,2,
$$

which provide the retailer's price reaction functions to his advertising and to the manufacturers' decision variables, namely:

$$
p_{i}=\frac{1}{2}\left(a_{m i} \alpha+a_{r i} \beta+v+w_{i}\right), \quad p_{s}=\frac{1}{2}\left(a_{s} \beta+v_{s}\right) .
$$

The retailer's objective function is a strictly concave function iff $\gamma-2 \theta^{2}+1>0$.

In stage 3, we insert the reaction functions in 4 into the manufacturer $i$ 's pricing problem to get

$$
\max _{w_{i}} M_{i}=w_{i} q_{i}-a_{m i}^{2},
$$

where $q_{i}$ is given by (1) after replacing the retail prices by the reaction functions in (.4). Then, we solve the manufacturers' first-order optimality conditions that characterize the Nash equilibrium between manufacturers $\frac{\partial M_{i}}{\partial w_{i}}=0, i=1,2$, to get the manufacturers' wholesale prices as functions of advertising efforts $a_{m i}, a_{s}$ and $a_{r i}$ such as:

$$
w_{i}=\frac{\Lambda_{1}\left(a_{m i} \alpha+a_{r i} \beta\right)+\left(1-\theta^{2}\right)\left(\gamma-\theta^{2}\right)\left(a_{m j} \alpha+a_{r j} \beta\right)+\Lambda_{2}\left(a_{s} \beta \theta-v+v_{s} \theta\right)}{\left(\gamma-\theta^{2}\right)^{2}-4\left(\theta^{2}-1\right)},
$$

for $i, j=1,2, i \neq j$, where

$$
\begin{aligned}
& \Lambda_{1}=\left(\gamma-\theta^{2}\right)^{2}-2\left(\theta^{2}-1\right)^{2} \\
& \Lambda_{2}=-\gamma(1+\gamma)+2-3 \theta^{2}(1-\gamma)
\end{aligned}
$$

The manufacturers' objective function is strictly concave iff $\gamma-2 \theta^{2}+1>0$. The expressions in .6 are then inserted into the retailer's price reaction functions in .4 and into the retailer's profit function. Now we solve the retailer's advertising problem in stage 2 of the game. The retailer's problem is given by

$$
\max _{a_{r i}, a_{s}} R=\sum_{i=1,2}\left[\left(p_{i}-w_{i}\right) q_{i}-a_{r i}^{2}\right]+p_{s} q_{s}-a_{s}^{2}
$$


where $q_{i}$ is given by (1) and $q_{s}$ in (2) and $p_{i}, p_{s}, i=1,2$ have been replaced by their expressions in (.4) and $w_{i}, i=2$, by their expressions in (.6). Solving the retailer's first-order conditions given by

$$
\frac{\partial R}{\partial a_{r i}}=\frac{\partial R}{\partial a_{s}}=0, i=1,2,
$$

the retailer's advertising strategies as functions of the manufacturers advertising variable are obtained

$$
\begin{aligned}
& a_{r i}=\frac{\left(\left(\beta^{2}-4\right) v+4 v_{s} \theta\right) \Lambda_{3}+4 \alpha \Lambda_{4} a_{m j}+\alpha\left(1-\theta^{2}\right) \Lambda_{5} a_{m i}}{\Lambda_{3} \Lambda_{6}}, i, j=1,2, i \neq j, \\
& a_{s}=-\beta \frac{4 \theta\left(\theta^{2}-1\right)^{2}\left(a_{m 1} \alpha+a_{m 2} \alpha+2 v\right)+v_{s} \Lambda_{7}}{\Lambda_{6}}
\end{aligned}
$$

where

$$
\begin{aligned}
\Lambda_{3} & =\beta^{2}\left(\theta^{2}-1\right)^{2}+4(\gamma-1)\left(\gamma-3 \theta^{2}+2\right)^{2}, \\
\Lambda_{4} & =\left(\beta^{2}-4\right) \gamma\left(\gamma^{2}+3 \theta^{2}\left(\theta^{2}-1\right)\right)+\beta^{2}\left(\theta^{2}-2 \theta^{4}\right)+4 \theta^{6}, \\
\Lambda_{5} & =\beta^{4}\left(1-\theta^{2}\right)+4 \beta^{2}\left(3 \gamma\left(\gamma-2 \theta^{2}\right)+8 \theta^{2}-5\right)-16\left(3 \gamma\left(\gamma-2 \theta^{2}\right)-\theta^{2}\left(\theta^{2}-8\right)-4\right), \\
\Lambda_{6} & =\beta^{4}\left(\theta^{2}-1\right)^{2}-4 \beta^{2}\left(\gamma^{2}(\gamma-3)-3(\gamma-2) \theta^{2}\left(\theta^{2}-2\right)+5\right) \\
& +16\left(\gamma+\theta^{2}-2\right)^{2}\left(\gamma-2 \theta^{2}+1\right), \\
\Lambda_{7} & =\beta^{2}\left(\theta^{2}-1\right)^{2}-4\left(\gamma^{2}(\gamma-3)-3 \gamma \theta^{2}\left(\theta^{2}-2\right)(5-3 \gamma)+4\right) .
\end{aligned}
$$

The retailer's concavity conditions are given by

$$
\begin{aligned}
& \left(\gamma-2 \theta^{2}+1\right) \Lambda_{8}>0, \\
& \left(\gamma-2 \theta^{2}+1\right) \Lambda_{9}>0 \\
& \left(\gamma-2 \theta^{2}+1\right) \Lambda_{10} \Lambda_{11}<0
\end{aligned}
$$

where

$$
\begin{aligned}
\Lambda_{8} & =18 \beta^{2}\left(1-\theta^{2}\right)^{3}\left(3 \gamma\left(\gamma-2 \theta^{2}\right)-\left(\theta^{2}-2\right)^{2}+4 \theta^{2}\right) \\
& +72(1-\gamma)\left(\gamma-3 \theta^{2}+2\right)^{2}\left(\gamma-2 \theta^{2}+1\right)\left(\gamma+\theta^{2}-2\right)^{2}, \\
\Lambda_{9} & =\beta^{4}\left(\theta^{2}-1\right)^{4}-8 \beta^{2}\left(3 \gamma\left(\gamma-2 \theta^{2}\right)-\left(\theta^{2}-2\right)^{2}+4 \theta^{2}\right) \\
& -16(\gamma-1)\left(\gamma-3 \theta^{2}+2\right)^{2}\left(\gamma-2 \theta^{2}+1\right)\left(\gamma+\theta^{2}-2\right)^{2}, \\
\Lambda_{10} & =\beta^{2}\left(\theta^{2}-1\right)^{2}+4(\gamma-1)\left(\gamma-3 \theta^{2}+2\right)^{2}, \\
\Lambda_{11} & =\beta^{4}\left(\theta^{2}-1\right)^{2}-4 \beta^{2}\left(\gamma^{2}(\gamma-3)-3(\gamma-2) \theta^{2}\left(\theta^{2}-2\right)+5\right) \\
& +16\left(\gamma+\theta^{2}-2\right)^{2}\left(\gamma-2 \theta^{2}+1\right) .
\end{aligned}
$$

The expressions in .8 and $(.9)$ are then inserted in the pricing reaction functions of the manufacturers in (.6) and of the retailer in (.4). Next, these functions are placed in the manufacturer $i$ 's advertising problem in stage 1 which is

$$
\max _{a_{m i}} M_{i}=w_{i} q_{i}-a_{m i}^{2},
$$

where $q_{i}$ is given by (1) and $p_{i}, p_{s}, i=1,2$ have been replaced by their expressions in (.4), $w_{i}, i=2$, by their expressions in (.6) and $a_{r i}, a_{s}, i=1,2$, by their expressions in (.8) and (.9).

Solving the first-order optimality conditions for a Nash equilibrium between the manufacturers $\left(\frac{\partial M_{i}}{\partial a_{m i}}=0, i=\right.$ $1,2)$ gives the equilibrium solution for $a_{m_{i}}$ in $A P^{S B}$. The manufacturers' concavity condition is as follows:

$$
-2 \Lambda_{10}^{2} \Lambda_{11}^{2}+64 \alpha^{2}\left(\theta^{2}-1\right)\left((1-\gamma)\left(2 \theta^{2}-(\gamma+1)\right)\right) \Lambda_{12}<0 .
$$




$$
\begin{aligned}
\Lambda_{14} & =\left[\beta^{4}\left(\theta^{2}-1\right)^{3}+2 \beta^{2}\left(\gamma^{3}\left(\gamma-4 \theta^{2}\right)+6 \gamma^{2}\left(2 \theta^{2}-1\right)+\gamma\left(9 \theta^{4}-26 \theta^{2}+13\right) \theta^{2}\right.\right. \\
& \left.-14 \theta^{6}+41 \theta^{4}-36 \theta^{2}+10\right)-8\left[\gamma^{3}\left(\gamma-4 \theta^{2}\right)+6 \gamma^{2}\left(2 \theta^{2}-1\right)\right. \\
& \left.\left.+4 \gamma\left(2 \theta^{4}-6 \theta^{2}+3\right) \theta^{2}+3 \theta^{8}-20 \theta^{6}+42 \theta^{4}-32 \theta^{2}+8\right]\right]^{2} .
\end{aligned}
$$

Finally, the obtained equilibrium is inserted in the manufacturers and retailers' reaction functions to obtain the equilibrium retail and wholesale prices, and the retailer's advertising efforts as functions of the model's parameters as shown in Proposition 2.

The $P A^{S B}$ game

In this case, the equilibrium solution is obtained by solving a four-stage game. We follow a similar approach as for $A P^{S B}$. To solve the game backwards, we start by stage 4 and solve the retailer's advertising problem given by

$$
\max _{a_{r i}, a_{s}} R=\sum_{i=1,2}\left[\left(p_{i}-w_{i}\right) q_{i}-a_{r i}^{2}\right]+p_{s} q_{s}-a_{s}^{2}
$$

where $q_{i}$ is given by (11) and $q_{s}$ by (2) and solve the following first-order conditions:

$$
\frac{\partial R}{\partial a_{r i}}=\frac{\partial R}{\partial a_{s}}=0, \quad i=1,2,
$$

which provide the retailer's advertising reaction functions to his pricing and to the manufacturers' decision variables, namely, for $i, j=1,2, i \neq j$ :

$$
\begin{aligned}
& a_{r i}=\frac{\beta\left(\left(1-\theta^{2}\right)\left(w_{i}-p_{i}\right)+\left(\theta^{2}-\gamma\right)\left(w_{j}-p_{j}\right)+(1-\gamma) \theta p_{s}\right)}{2(\gamma-1)\left(\gamma-2 \theta^{2}+1\right)}, \\
& a_{s}=\frac{\beta\left(\theta\left(-p_{1}-p_{2}+w_{1}+w_{2}\right)+(\gamma+1) p_{s}\right)}{2\left(\gamma-2 \theta^{2}+1\right)} .
\end{aligned}
$$

It can be easily shown that the concavity conditions are satisfied for any values of the model parameters.

In stage 3, the manufacturer $i$ 's advertising problem reads

$$
\max _{a_{m i}} M_{i}=w_{i} q_{i}-a_{m i}^{2},
$$

where $q_{i}$ is given by (1) and we insert the obtained retailer's reaction functions in (.16) and (.17). The first-order optimality conditions for a Nash equilibrium between the manufacturers $\frac{\partial M_{i}}{\partial a_{m i}}=0, i=1,2$ are solved to get the manufacturers' advertising as functions of pricing strategies $p_{i}, p_{s}$ and $w_{i}$ such as:

$$
a_{m i}=\frac{\alpha\left(\theta^{2}-1\right) w_{i}}{2(\gamma-1)\left(\gamma-2 \theta^{2}+1\right)}, i=1,2 .
$$

The manufacturers' concavity condition is satisfied for any values of the model parameters $\left(\frac{\partial^{2} M_{i}}{\partial a_{m i}^{2}}=-2<0\right)$. In stage 2, we solve the retailer's pricing problem given by

$$
\max _{p_{i}, p_{s}} R=\sum_{i=1,2}\left[\left(p_{i}-w_{i}\right) q_{i}-a_{r i}^{2}\right]+p_{s} q_{s}-a_{s}^{2}
$$

where $q_{i}$ is given by (1) and $q_{s}$ by (2) and the retailer's and manufacturers' advertising reaction functions $a_{r i}$, $a_{s}$ and $a_{m i}$ have been replaced by (.16), .17) and (.19), respectively. The solution of the retailer's first-order conditions

$$
\frac{\partial R}{\partial p_{i}}=\frac{\partial R}{\partial p_{s}}=0, \quad i=1,2,
$$


where

$$
\begin{aligned}
\Omega_{1} & =\left(-\theta^{2}\left(\alpha^{2}-4(1-\gamma)\right)+\alpha^{2}+2\left(\gamma^{2}-1\right)\right)\left(\left(\beta^{2}-4\right) \gamma+4 \theta^{2}\right), \\
\Omega_{2} & =\alpha^{2}\left(\theta^{2}-1\right)\left(\left(\beta^{2}-4\right)\left(\beta^{2}+4\left(\gamma^{2}-1\right)\right)+4 \theta^{2}\left(\beta^{2}-8(1-\gamma)\right)\right) \\
& +(1-\gamma)\left(2 \theta^{2}-\gamma-1\right)\left(8 \theta^{2}\left(3 \beta^{2}+8 \gamma-8\right)+\left(4-\beta^{2}\right)\left(\beta^{4}-6 \beta^{2}+8\left(1-\gamma^{2}\right)\right)\right), \\
\Omega_{3} & =2(1-\gamma)\left(4-4 \gamma-\beta^{2}\right)\left(\gamma-2 \theta^{2}+1\right)\left(\left(4-\beta^{2}\right)(\gamma+1) v-\beta^{2} v_{s} \theta-8 v \theta^{2}\right), \\
\Omega_{4} & =2(1-\gamma)\left(\gamma-2 \theta^{2}+1\right)\left(2 \beta^{2} v \theta+v_{s}\left(\beta^{2}-4(1+\gamma)+8 \theta^{2}\right)\right), \\
\Omega_{5} & =\alpha^{2}\left(\theta^{2}-1\right)+2(1-\gamma)\left(\gamma-2 \theta^{2}+1\right) .
\end{aligned}
$$

The retailer's concavity conditions are satisfied iff

$$
\begin{aligned}
& \beta^{2}\left(\gamma^{2}\left(\theta^{2}+1\right)-4 \gamma \theta^{2}+2 \theta^{4}-\theta^{2}+1\right)+4\left(1-\theta^{2}\right)(1-\gamma)\left(2 \theta^{2}-\gamma-1\right)<0, \\
& \left(\beta^{2}-4(1-\gamma)\right)\left(\beta^{2}\left(2 \theta^{2}+1\right)-4(1+\gamma)+8 \theta^{2}\right)>0, \\
& \beta^{6}-12 \beta^{4}-16 \beta^{2}\left(\gamma^{2}+2 \theta^{2}-3\right)+64(1-\gamma)\left(2 \theta^{2}-\gamma-1\right)<0 .
\end{aligned}
$$

In stage 1, the manufacturers' pricing problem is

$$
\max _{w_{i}} M_{i}=w_{i} q_{i}-a_{m i}^{2},
$$

where $q_{i}$ is given by (1) and we insert the obtained retailer's advertising reaction functions in (.16) and (.17), the manufacturers' advertising reaction functions in .19 and the retailer's pricing reaction functions in $(.21)$ and $(.22)$.

Solving the first-order optimality condition for a Nash equilibrium between the manufacturers $\left(\frac{\partial M_{i}}{\partial w_{i}}=0, i=\right.$ $1,2)$ gives the equilibrium solution for $w_{i}$ in $P A^{S B}$. The manufacturers' concavity condition is satisfied iff

where

$$
\frac{\alpha^{2} \beta^{6}\left(\theta^{2}-1\right)^{2}+4 \beta^{4} \Omega_{6}+16 \beta^{2} \Omega_{7}+\Omega_{8}}{\left(\beta^{2}-4(1-\gamma)\right)\left(\left(\beta^{2}-4\right)\left(\beta^{2}-4(1+\gamma)\right)-32 \theta^{2}\right)}>0
$$

$$
\begin{aligned}
& \Omega_{6}=\alpha^{2}\left(\theta^{2}-1\right)\left(\gamma^{2}-(2 \gamma+1) \theta^{2}+2\right)-2(\gamma-1)^{2}\left(\gamma-2 \theta^{2}+1\right)^{2}, \\
& \Omega_{7}=4(\gamma-1)^{2}\left(\gamma-2 \theta^{2}+1\right)^{2}+\alpha^{2}\left(1-\theta^{2}\right)\left(\gamma^{2}+((\gamma-4) \gamma-1) \theta^{2}+2 \theta^{4}+1\right), \\
& \Omega_{8}=128(\gamma-1)^{2}\left(\theta^{2}-1\right)\left(\gamma-2 \theta^{2}+1\right)^{2} .
\end{aligned}
$$

Finally, the equilibrium wholesale prices are inserted in the manufacturers' and retailer's reaction functions to obtain the equilibrium retail price, and the retailer's advertising efforts as functions of the model's parameters as shown in Proposition 3.

\section{Appendix 2. Comparison of equilibrium strategies}

Numerical comparison of equilibrium quantities, prices and advertising strategies for $S$ vs. $S^{S B}, P A$ vs. $P A^{S B}$, and $A P$ and $A P^{S B}$ for the same numerical values used in the paper gives the results in Table A.1 In this table, the signs "-" and " \pm " mean that the effect of the store brand introduction is negative or can be either positive or negative depending on the model's parameters, respectively. Note that when results correspond to " \pm ", in most of the cases and in the great part of the feasible region, the "-" sign applies. The "+" sign only applies in a small part of the feasible region, close to the frontier of the equilibrium feasibility domain. 


\begin{tabular}{|c|c|c|c|}
\hline & $S$ vs. $S^{S B}$ & $A P$ vs. $A P^{S B}$ & $P A$ vs. $P A^{S B}$ \\
\hline$w$ & $\begin{array}{l}- \\
\pm(\theta=0.15, \gamma=0.2)\end{array}$ & $\begin{array}{l} \pm \\
-(\theta=0.15, \gamma=0.6)\end{array}$ & $\begin{array}{l} \pm \\
-(\theta=0.15, \gamma=0.6) \\
-(\theta=0.25, \gamma=0.2) \\
-(\theta=0.35, \gamma=0.2,0.4)\end{array}$ \\
\hline$a_{m}$ & $\begin{array}{l} \pm \\
-(\theta=0.15, \gamma=0.4,0.6) \\
-(\theta=0.25, \gamma=0.6)\end{array}$ & $\begin{array}{l} \pm \\
-(\theta=0.15, \gamma=0.6)\end{array}$ & $\begin{array}{l} \pm \\
-(\theta=0.15, \gamma=0.6)\end{array}$ \\
\hline$p$ & $\begin{array}{l} \pm \\
-(\theta=0.15, \gamma=0.4,0.6) \\
-(\theta=0.25, \gamma=0.6)\end{array}$ & $\begin{array}{l} \pm \\
-(\theta=0.15, \gamma=0.6)\end{array}$ & $\begin{array}{l} \pm \\
-(\theta=0.15, \gamma=0.6) \\
-(\theta=0.25, \gamma=0.2) \\
-(\theta=0.35, \gamma=0.2,0.4)\end{array}$ \\
\hline$a_{r}$ & $\begin{array}{l} \pm \\
-(\theta=0.15, \gamma=0.4,0.6) \\
-(\theta=0.25, \gamma=0.6)\end{array}$ & $\begin{array}{l} \pm \\
-(\theta=0.15, \gamma=0.6)\end{array}$ & $\begin{array}{l} \pm \\
-(\theta=0.15, \gamma=0.4,0.6) \\
-(\theta=0.25, \gamma=0.6)\end{array}$ \\
\hline$q_{i}$ & $\begin{array}{l} \pm \\
-(\theta=0.15, \gamma=0.4,0.6) \\
-(\theta=0.25, \gamma=0.6)\end{array}$ & $\begin{array}{l} \pm \\
-(\theta=0.15, \gamma=0.6)\end{array}$ & $\begin{array}{l} \pm \\
-(\theta=0.15, \gamma=0.4,0.6) \\
-(\theta=0.25, \gamma=0.6)\end{array}$ \\
\hline
\end{tabular}

* When results correspond to " \pm ", in most cases, the "-" sign applies with the "+" sign only applying to a very small part of the feasible region.

Table A.1 Effects of SB introduction on pricing and advertising strategies and quantities

Numerical comparison of equilibrium quantities, prices and advertising strategies for $S^{S B}$ vs. $A P^{S B}, S^{S B}$ vs. $P A^{S B}$, and $A P^{S B}$ and $P A^{S B}$ for the same numerical values used in the paper gives the results in Table A. 2 The signs,+- and \pm in scenario $X$ vs. $Y$ mean that variable $z$ satisfies $z^{X} \geq z^{Y}, z^{X}<z^{Y}$ and $z^{X} \lessgtr z^{Y}$, respectively.

\begin{tabular}{|l|l|l|l|}
\hline & $S^{S B}$ vs. $A P^{S B}$ & $S^{S B}$ vs. $P A^{S B}$ & $A P^{S B}$ vs. $P A^{S B}$ \\
\hline$w$ & \pm & $\begin{array}{l} \pm \\
+(\theta=0.35, \gamma=0.2)\end{array}$ & $\begin{array}{l}+(\theta=0.15, \gamma=0.2) \\
\pm\end{array}$ \\
\hline$a_{m}$ & + & \pm & $\begin{array}{l} \pm \\
-(\theta=0.35, \gamma=0.2,0.4)\end{array}$ \\
\hline & \pm & \pm & \pm \\
$p$ & $+(\theta=0.15, \gamma=0.2)$ & & $+(\theta=0.15, \gamma=0.6)$ \\
& $+(\theta=0.25, \gamma=0.2)$ & & \\
\hline$a_{r}$ & $+(\theta=0.35, \gamma=0.2)$ & & - \\
\hline & + & \pm & \pm \\
$q_{i}$ & + & \pm & $-(\theta=0.25, \gamma=0.2)$ \\
& & & $-(\theta=0.35, \gamma=0.2)$ \\
\hline$p_{S}$ & - & \pm & + \\
\hline$a_{S}$ & - & \pm & + \\
\hline & & & \pm \\
$q_{S}$ & - & $+(\theta=0.25, \gamma=0.2)$ \\
& & $+(\theta=0.35, \gamma=0.2,0.4)$ \\
\hline
\end{tabular}

Table A.2 Comparison of equilibrium prices, advertising strategies and quantities in the SB games

\section{References}

Amrouche, N., \& Yan, R. (2015). Aggressive or partnership strategy: Which choice is better for the national brand? International Journal of Production Economics, 166, 50-63.

Bagwell, K. (1995). Commitment and observability in games. Games and Economic Behavior, 8, 271-280.

BIA (2020). Bia's u.s. local advertising forecast. Accessed: 2020-12-30.

Borrell, A. (2018). Preliminary results from borrell's 2018 local advertising survey. Accessed: 2021-02-11.

Cai, G., Dai, Y., \& Zhou, S. X. (2012). Exclusive channels and revenue sharing in a complementary goods market. Marketing Science, 31, 172-187.

Chen, J., \& Dimitrov, S. (2015). National and store brand advertising strategies. Journal of the Operational Research Society, 66, 1237-1249.

Chintagunta, P. K. (1993). Investigating purchase incidence, brand choice and purchase quantity decisions of households. Marketing Science, 12, 184-208. 
Choi, S. C., \& Coughlan, A. T. (2006). Private label positioning: Quality versus feature differentiation from the national brand. Journal of Retailing, 82, 79-93.

Choi, T.-M., Li, Y., \& Xu, L. (2013). Channel leadership, performance and coordination in closed loop supply chains. International Journal of Production Economics, 146, 371-380.

Chung, H., \& Lee, E. (2017). Store brand quality and retailer's product line design. Journal of Retailing, 93, 527-540.

Collins-Dodd, C., \& Lindley, T. (2003). Store brands and retail differentiation: the influence of store image and store brand attitude on store own brand perceptions. Journal of Retailing and Consumer Services, 10, 345-352.

van Damme, E., \& Hurkens, S. (1996). Commitment robust equilibria and endogenous timing. Games and Economic Behavior, 15, 290-311.

van Damme, E., \& Hurkens, S. (1999). Endogenous stackelberg leadership. Games and Economic Behavior, 28, $105-129$.

van Damme, E., \& Hurkens, S. (2004). Endogenous price leadership. Games and Economic Behavior, 47, 404-420.

Ernest-Jones, S. (2019). 10 examples of local marketing that worked \& why. Accessed: 2021-02-11.

Etgar, M. (1977). Channel environment and channel leadership. Journal of Marketing Research, 14, 69-76.

Forbes, A. C. (2020). 12 ways a business can aim for a more local marketing approach. Accessed: 2021-02-12.

Gal-Or, E. (1985). Information sharing in oligopoly. Econometrica: Journal of the Econometric Society, 53, $329-343$.

Gal-Or, E. (1987). First mover disadvantages with private information. The Review of Economic Studies, 54, $279-292$.

Gázquez-Abad, J. C., \& Martínez-López, F. J. (2016). Understanding the impact of store flyers on purchase behaviour: An empirical analysis in the context of spanish households. Journal of Retailing and Consumer Services, 28, 263-273.

Gruca, T. S., Sudharshan, D., \& Kumar, K. R. (2001). Marketing mix response to entry in segmented markets. International Journal of Research in Marketing, 18, 53-66.

Guyt, J., \& Gijsbrechts, E. (2018). On consumer choice patterns and the net impact of feature promotions. International Journal of Research in Marketing, 35, 490-508.

Hamilton, J. H., \& Slutsky, S. M. (1990). Endogenous timing in duopoly games: Stackelberg or cournot equilibria. Games and Economic Behavior, 2, 29-46.

Helmes, K., Schlosser, R., \& Weber, M. (2013). Optimal advertising and pricing in a class of general new-product adoption models. European Journal of Operational Research, 229, 433-443.

Herrington, J. D., \& Dempsey, W. A. (2005). Comparing the current effects and carryover of national-, regional-, and local-sponsor advertising. Journal of Advertising Research, 45, 60-72.

Ingene, C. A., \& Parry, M. E. (2007). Bilateral monopoly, identical distributors, and game-theoretic analyses of distribution channels. Journal of the Academy of Marketing Science, 35, 586-602.

Ingene, C. A., Taboubi, S., \& Zaccour, G. (2012). Game-theoretic coordination mechanisms in distribution channels: Integration and extensions for models without competition. Journal of Retailing, 88, 476-496.

IRI, B. (2020). Consumer spending tracker for measured channels. Accessed: 2020-12-30.

Jørgensen, S., Sigue, S.-P., \& Zaccour, G. (2001). Stackelberg leadership in a marketing channel. International Game Theory Review, 3, 13-26.

Kalra, A., \& Shi, M. (2010). Consumer value-maximizing sweepstakes and contests. Journal of Marketing Research, 47, 287-300.

Karray, S. (2013). Periodicity of pricing and marketing efforts in a distribution channel. European Journal of Operational Research, 228, 635-647.

Karray, S., \& Martín-Herrán, G. (2008). Investigating the relationship between advertising and pricing in a channel with private label offering: A theoretic model. Review of Marketing Science, 6.

Karray, S., \& Martín-Herrán, G. (2009). A dynamic model for advertising and pricing competition between national and store brands. European Journal of Operational Research, 193, 451-467.

Karray, S., \& Martín-Herrán, G. (2019). Fighting store brands through the strategic timing of pricing and advertising decisions. European Journal of Operational Research, 275, 635-647.

Karray, S., Martín-Herrán, G., \& Zaccour, G. (2017). Assessing the profitability of cooperative advertising programs in competing channels. International Journal of Production Economics, 187, 142-158.

Karray, S., \& Zaccour, G. (2005). A differential game of advertising for national and store brands. In Dynamic Games: Theory and Applications (pp. 213-229). Springer.

Karray, S., \& Zaccour, G. (2006). Could co-op advertising be a manufacturer's counterstrategy to store brands? Journal of Business Research, 59, 1008-1015.

Krishnamoorthy, A., Prasad, A., \& Sethi, S. P. (2010). Optimal pricing and advertising in a durable-good duopoly. European Journal of Operational Research, 200, 486-497.

Kumar, V., \& Leone, R. (1988). Measuring the effect of retail store promotions on brand and store substitution. Journal of Marketing Research, 25, 178-185.

Liu, B., Cai, G., \& Tsay, A. A. (2014). Advertising in asymmetric competing supply chains. Production and Operations Management, 23, 1845-1858.

Liu, B., Ma, S., Guan, X., \& Xiao, L. (2018). Timing of sales commitment in a supply chain with manufacturer-quality and retailereffort induced demand. International Journal of Production Economics, 195, 249-258.

Liu, J., \& Ke, H. (2020). Firms' pricing strategies under different decision sequences in dual-format online retailing. Soft Computing, $24,7811-7826$.

Lus, B., \& Muriel, A. (2009). Measuring the impact of increased product substitution on pricing and capacity decisions under linear demand models. Production and Operations Management, 18, 95-113.

Madden, P., \& Pezzino, M. (2019). Endogenous price leadership with an essential input. Games and Economic Behavior, 118, 47-59.

Mailath, G. J. (1993). Endogenous sequencing of firm decisions. Journal of Economic Theory, 59, 169-182.

Maiti, T., \& Giri, B. (2017). Two-way product recovery in a closed-loop supply chain with variable markup under price and quality dependent demand. International Journal of Production Economics, 183, 259-272.

Martenson, R. (2007). Corporate brand image, satisfaction and store loyalty: A study of the store as a brand, store brands and manufacturer brands. International Journal of Retail E Distribution Management, 35, 544-555.

Matsui, K. (2018). When and what wholesale and retail prices should be set in multi-channel supply chains? European Journal of Operational Research, 267, 540-554. 
Matsui, K. (2020). Optimal bargaining timing of a wholesale price for a manufacturer with a retailer in a dual-channel supply chain. European Journal of Operational Research, 287, 225-236.

Meza, S., \& Sudhir, K. (2010). Do private labels increase retailer bargaining power? Quantitative Marketing and Economics, 8 , 333-363.

Narasimhan, C., \& Wilcox, R. T. (1998). Private labels and the channel relationship: A cross-category analysis. The Journal of Business, 71, 573-600.

Pauwels, K. (2007). How retailer and competitor decisions drive the long-term effectiveness of manufacturer promotions for fast moving consumer goods. Journal of Retailing, 83, 297-308.

Pauwels, K., \& Srinivasan, S. (2004). Who benefits from store brand entry? Marketing Science, 23, 364-390.

Pauwels, K., \& Srinivasan, S. (2009). Pricing of national brands versus store brands: Market power components, findings and research opportunities. In V. R. Rao (Ed.), Handbook of Pricing Research in Marketing chapter 12. (pp. 258-282). Cheltenham, UK: Edward Elgar Publishing.

Perdikaki, O., Kostamis, D., \& Swaminathan, J. M. (2016). Timing of service investments for retailers under competition and demand uncertainty. European Journal of Operational Research, 254, 188-201.

PLMA (2020). Industry news. Accessed: 2020-12-30.

Raju, J. S., Sethuraman, R., \& Dhar, S. K. (1995). The introduction and performance of store brands. Management Science, 41, 957-978.

Redman, R. (2020). Store brand sales surge in q1 from covid-19 stock-up purchases. Accessed: 2020-12-30.

Reed, R. (2020). Cmos need to think and act locally in the age of covid-19 and beyond. Accessed: 2021-02-12.

Reid, L. N., King, K. W., Martin, H. J., \& Soh, H. (2005). Local advertising decision makers' perceptions of media effectiveness and substitutability. Journal of Media Economics, 18, 35-53.

Ru, J., Shi, R., \& Zhang, J. (2015). Does a store brand always hurt the manufacturer of a competing national brand? Production and Operations Management, 24, 272-286.

Samuelson, P. A. (1974). Complementarity: An essay on the 40th anniversary of the hicks-allen revolution in demand theory. Journal of Economic Literature, 12, 1255-1289.

Sayman, S., Hoch, S. J., \& Raju, J. S. (2002). Positioning of store brands. Marketing Science, 21, 378-397.

Schlosser, R. (2017). Stochastic dynamic pricing and advertising in isoelastic oligopoly models. European Journal of Operational Research, 259, 1144-1155.

Schul, P. L., Pride, W. M., \& Little, T. L. (1983). The impact of channel leadership behavior on intrachannel conflict. Journal of Marketing, 47, 21-34.

Scott Morton, F., \& Zettelmeyer, F. (2004). The strategic positioning of store brands in retailer-manufacturer negotiations. Review of Industrial Organization, 24, 161-194.

Sethuraman, R. (2009). Assessing the external validity of analytical results from national brand and store brand competition models. Marketing Science, 28, 759-781.

Soberman, D. A., \& Parker, P. M. (2006). The economics of quality-equivalent store brands. International Journal of Research in Marketing, 23, 125-139.

Spence, M. (1976). Product differentiation and welfare. The American Economic Review, 66, 407-414.

Steenkamp, J.-B. E., Van Heerde, H. J., \& Geyskens, I. (2010). What makes consumers willing to pay a price premium for national brands over private labels? Journal of Marketing Research, 47, 1011-1024.

Stevenson, A. (2018). Top 5 examples of local advertising. Accessed: 2021-02-10.

Sudhir, K. (2001). Structural analysis of manufacturer pricing in the presence of a strategic retailer. Marketing Science, 20, $244-264$.

Sudhir, K., \& Talukdar, D. (2004). Does store brand patronage improve store patronage? Review of Industrial Organization, 24, 143-160.

Tang, Y.-C., Wang, Y.-M., \& Huang, J.-Y. (2014). Optimal promotional strategy for intra-category cross-selling: An application to culinary products in taiwan. British Food Journal, 16, 80-90.

Weitz, B. A., \& Wensley, R. (2002). Handbook of marketing. Sage.

Yan, N., Liu, Y., Xu, X., \& He, X. (2020). Strategic dual-channel pricing games with e-retailer finance. European Journal of Operational Research, 283, 138-151. 
Click here to access/download

\section{LaTeX Source Files}

NB-SB-competition-IJPE-R1-Oct19.tex 
Click here to access/download

\section{LaTeX Source Files}

NB-SB-bib.bib 
Click here to access/download

\section{LaTeX Source Files}

Figures.zip 